\title{
Suppression of isoprenylcysteine
} carboxylmethyltransferase compromises DNA damage repair

\author{
Jingyi Tang ${ }^{1}$, Patrick J Casey ${ }^{1,2}$ (D), Mei Wang ${ }^{1,3}$ (D)
}

\begin{abstract}
DNA damage is a double-edged sword for cancer cells. On the one hand, DNA damage-induced genomic instability contributes to cancer development; on the other hand, accumulating damage compromises proliferation and survival of cancer cells. Understanding the key regulators of DNA damage repair machinery would benefit the development of cancer therapies that induce DNA damage and apoptosis. In this study, we found that isoprenylcysteine carboxylmethyltransferase (ICMT), a posttranslational modification enzyme, plays an important role in DNA damage repair. We found that ICMT suppression consistently reduces the activity of MAPK signaling, which compromises the expression of key proteins in the DNA damage repair machinery. The ensuing accumulation of DNA damage leads to cell cycle arrest and apoptosis in multiple breast cancer cells. Interestingly, these observations are more pronounced in cells grown under anchorage-independent conditions or grown in vivo. Consistent with the negative impact on DNA repair, ICMT inhibition transforms the cancer cells into a "BRCA-like" state, hence sensitizing cancer cells to the treatment of PARP inhibitor and other DNA damage-inducing agents.
\end{abstract}

DOI 10.26508/Isa.202101144 | Received 25 June 2021 | Revised 18 September 2021 | Accepted 20 September 2021 | Published online 5 October 2021

\section{Introduction}

DNA damage response plays important roles in cancer development and is a major focus of attention in cancer therapy (1,2). DNA damage, which can be the result of radiation $(3,4)$, drugs (5), oxidative stress $(6)$, or replicative stress $(7,8)$, triggers DNA repair pathways and cell cycle check points and can ultimately lead to programmed cell death $(9,10,11)$. The resilience and adaptation to DNA damage-induced genomic instability contributes to cancer development (12); many cancers arise because of an impairment of the DNA damage repair machinery and associated genomic instability $(13,14)$. Interestingly, this impairment of DNA damage repair becomes a vulnerability when overwhelmed, forming the rationale for targeted therapy using DNA damage-inducing agents for selected cancers (15). A prime example is inhibition of poly ADPribose polymerase 1 (PARP1), an enzyme important for the DNA repair in many ways, with particular involvement in repairing single-strand breaks $(16,17)$. Inhibition of PARP activity can lead to the accumulation of DNA double-strand breaks in proliferating cells (18). The cancers that have existing deficiencies in DNA repair machinery, such as those with BRCA1/2 mutations $(19,20)$ or PTEN dysfunction (21), are particularly vulnerable to PARP inhibition because they rely more heavily on the single-strand break repair pathway in which PARP1 is a critical component. In contrast, cancer cells that have intact or elevated DNA repair capacity are significantly more resistant to PARP1-targeting agents $(22,23,24,25)$. For these cancers, PARP inhibitors have been used in combination with other targeted therapy to increase efficacy $(26,27,28,29,30)$. The ever-expanding efforts to understand the multifaceted regulation of DNA damage repair are identifying novel and effective synthetic lethality combinations to increase the responsiveness of cancers, particularly those having efficient DNA repair machinery that are otherwise resistant to DNA damage-inducing approaches such as irradiation or PARP inhibitor $(31,32)$.

In this study we have found that isoprenylcysteine carboxylmethyltransferase (ICMT), an enzyme of the protein prenylation pathway, plays an important role in DNA damage repair. Protein prenylation is a posttranslational modification process that occurs in all eukaryotes (33). The three-step enzymatic process starts with the addition of an isoprenoid lipid to the cysteine residue at the C-terminal consensus sequences, usually composed of CAAX (cysteine, aliphatic, and any amino acid), by one of the protein prenyltransferases $(34,35)$. The $\mathrm{C}$-terminal-AAX amino acids are then removed by the RCE1 endopeptidase $(36,37,38)$. The last step is the cysteine carboxylmethylation catalyzed by ICMT, which completes the post-prenylation processing that regulates the functions of various substrate proteins, among them the oncogenic RAS GTPases $(39,40,41,42)$. In the past decade, studies have demonstrated that suppression of ICMT reduces tumorigenesis and cancer

${ }^{1}$ Duke-NUS Medical School, Program in Cancer and Stem Cell, Singapore, Singapore ${ }^{2}$ Department of Pharmacology and Cancer Biology, Duke University School of Medicine, Durham, NC, USA ${ }^{3}$ Department of Biochemistry, National University of Singapore, Singapore 117596 
progression of various human cancers $(42,43,44,45,46,47)$. Although the complete mechanism of ICMT regulation of cell signaling is still an active area of investigation, it is clear that ICMT inhibition, either genetically or pharmacologically, affects the downstream signaling of ICMT substrates to regulate essential cell functions such as proliferation and survival $(48,49,50)$.

The MAPK signaling cascade, also known as the Ras-Raf-MEK-ERK pathway, plays an important role in transducing extracellular signals to cellular response (51). Although it is often considered the most canonical downstream pathway of oncogenic RAS, MAPK signaling responds to many stimuli and has extensive cross-talk with other signaling components. As such, the MAPK pathway is affected by growth factors/cytokines, drugs, and irradiation, among others, to influence many cellular events, such as proliferation and survival (51). Although the involvement of MAPK signaling in DNA damage and DNA damage repair pathways have been reported for many cancers, its multifaceted roles needs to be further clarified, especially the manners in which the pathway contributes in different cellular contexts $(52,53,54)$. In some situations, inhibiting ERK activation attenuates the DNA damage-induced cell death, suggesting a collaborative role of ERK in DNA damage or impairing DNA repair $(55,56,57)$. On the other hand, it is reported that ERK signaling is very important for homologous recombination (HR) repair in response to DNA damage $(58,59)$; inhibiting ERK function was reported to sensitize cancer cells to radiation-induced DNA damage, cell cycle arrest, and cell death (60).

The current study demonstrates that ICMT is important for the DNA damage repair function through its regulation of MAPK signaling and its impact on the expression of key DNA repair proteins. Inhibition of ICMT reduces ERK activation, compromises DNA damage repair, leads to the accumulation of DNA damage both at baseline growth condition and in response to DNA damage-inducing agents, inhibits proliferation and ultimately induces apoptosis. Furthermore, ICMT inhibition substantially increases the sensitivity of breast cancer cells to PARP1 inhibitor treatment, offering a novel therapeutic approach in the treatment of this group of cancers.

\section{Results}

Loss of ICMT induces apoptosis and abolishes the ability of MDAMB231 breast cancer cells to form colonies in soft agar and form tumors in vivo

To study the impact of ICMT suppression on tumorigenesis, we have generated, from parental MDA-MB231 cells, Icmt wild type, and multiple loss-of-Icmt isogenic cell lines, which we designated $\mathrm{cmt}^{+/+}$(WT) clones, and N1, N2, and N3 $\mathrm{cmt}^{-/-}$mixed clones (generated by guide RNA sequence 1, 2, and 3, respectively) (Fig 1A). MDA-MB231 cells have three copies of the ICMT gene, and the genotypes and the remnants of ICMT polypeptide of the coding sequences following CRISPR-mediated deletion are shown in Fig 1A. It is apparent from genomic DNA sequencing that the $1 \mathrm{cmt}^{-/-}$clones produce no functional ICMT protein because the C-terminal region of the protein that contains the catalytic domain is completely missing in the null cells (44). In the soft agar colony formation study typically used to assess transformation, we found that, whereas the $\mathrm{Icmt} \mathrm{cl}^{+/+}$cells form colonies readily, all the $1 \mathrm{cmt}^{-/-}$clones lost their ability to grow (Fig 1B and C), suggesting that ICMT is essential for the ability of MDA-MB231 cells to proliferate under an anchorageindependent condition-the defining feature of malignant cells. Inagar propidium iodide (PI) staining showed that the $\mathrm{Imt}^{-/-}$cells placed in soft agar underwent massive apoptosis (Figs 1D and S1), whereas under the adherent condition there was no significant elevation in apoptosis for $\mathrm{Icmt}^{-/-}$cells compared to the $\mathrm{lcmt^{+/+ }}$ cells (Fig S1). The in vivo tumor formation abilities of the $1 \mathrm{cmt}^{+/+}$and $\mathrm{Icmt} t^{-/-}$ MDA-MB231 cells are consistent to their ability to form soft agar colonies (Fig 1E), which is the expected result as the anchorageindependent growth is the in vitro study of choice in the assessment of malignant transformation. The model in Fig $1 \mathrm{~F}$ summarizes the essential role of ICMT in cancer cell colony formation and tumor formation, two properties that distinguish benign and malignant cells.

\section{ICMT inhibition causes G2/M cell cycle arrest}

In addition to increased apoptosis, we found that loss of ICMT function resulted in the increase of $\mathrm{PCDC2}(\mathrm{Th}$ 15) and cyclin B1 levels, consistent with cell cycle arrest at the G2/M phase (Fig 2A) $(61,62)$. To investigate this phenomenon further, we performed DNA content flow cytometry analysis on the $1 \mathrm{cmt}^{+/+}$and $1 \mathrm{cmt}^{-/-}$cells both at baseline and at 0 and $8 \mathrm{~h}$ following release from double thymidine block. Double thymidine block stops cell cycle progression at the G1/S phase; subsequence release allows observation of synchronized cell cycle progression. Flow cytometry analysis showed that the $/ \mathrm{cmt}^{-/-} \mathrm{N} 1, \mathrm{~N} 2$ and N3 cells have significant $\mathrm{G} 2 / \mathrm{M}$ arrest, which is especially apparent for the cells $8 \mathrm{~h}$ after the release from double thymidine block, at which point $1 \mathrm{cmt}^{+/+}$cells are almost back to the normal cell cycle distribution (Fig 2B).

To observe the dynamic cell cycle changes in liver cell populations, we established stable cell lines from $\mathrm{Icmt}^{+/+}$and $\mathrm{Icmt} \mathrm{CH}^{-/-}$ cells that expressed fluorescent cell cycle indicator proteins Citrine-Geminin and mCherry-Cdt1. Geminin and Cdt1 are two proteins whose degradation are regulated in cell cycle dependent manner (63). Therefore, the relative intensities of the fluorescent protein-tagged Geminin and Cdt1 allow identification of cell populations in different phase of cell cycle. At the G1 to S transition, both proteins are present, so the right upper quadrant in the flow diagram indicates the G1/S cells. The G1 cells and G2/M cells express Cdt1 and Geminin, respectively; hence they are represented in the right and upper left quadrants. The baseline distribution analysis showed that, in comparison to $\mathrm{Icmt}^{+/+}$cells, $1 \mathrm{cmt}^{-/-}$cells accumulate at $\mathrm{G} 2 / \mathrm{M}$ phase (Fig $2 \mathrm{C}$ ). To carefully examine the differences in cell cycle distribution between the $1 \mathrm{cmt}^{+/+}$and $\mathrm{Icmt} \mathrm{CH}^{-/-}$ cells using these fluorescent reporters, we again preformed double thymidine synchronization and release analysis. At the time of release from synchronization, the $I \mathrm{cmt}^{+/+}$cells accumulated at the G1/S transition point (Cdt1+/Geminin+ and Cdt1-/Geminin+), as expected. In contrast, the double thymidine treatment was less effective in synchronizing the $\mathrm{Imt}^{-/-}$cells at the G1/S phase-a significant number of cells were observed at the G2/M stage (Cdt1- / Geminin+) (Fig 2C). At $8 \mathrm{~h}$ after releasing from the block, we observed that $/ \mathrm{cmt}^{-/-}$cells continue to be arrested at G2/M phases, whereas the $1 \mathrm{cmt}^{+/+}$cells had essentially re-established the 
A

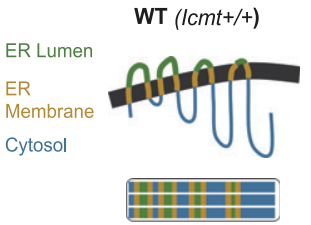

B

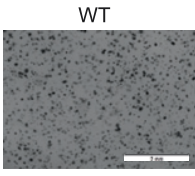

N2
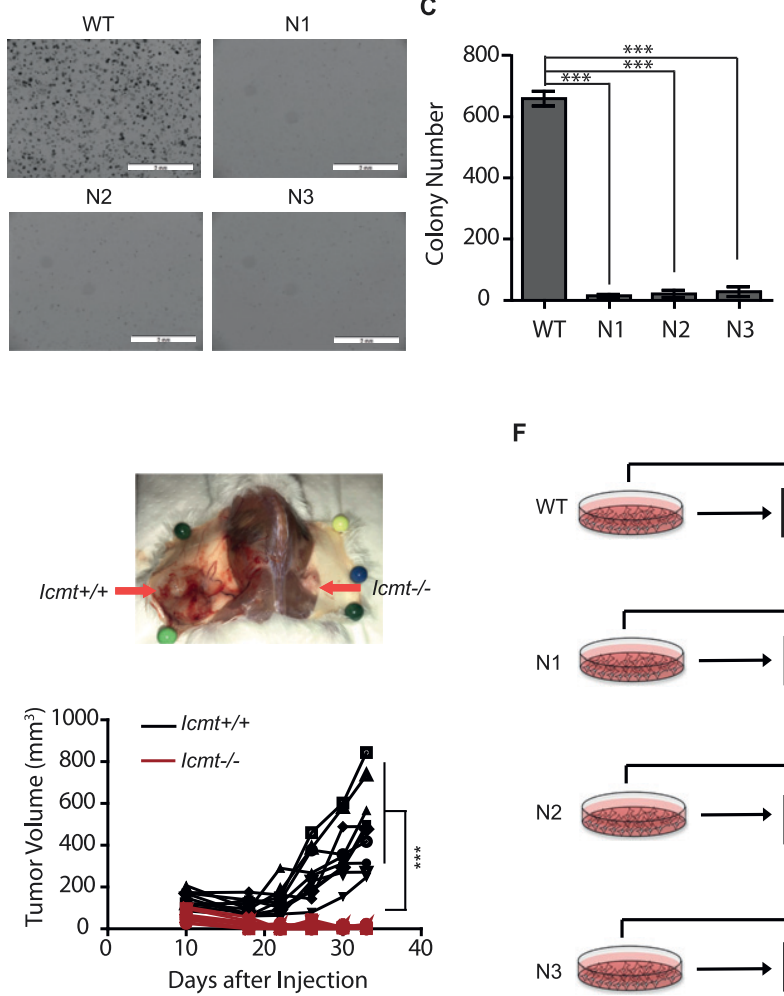

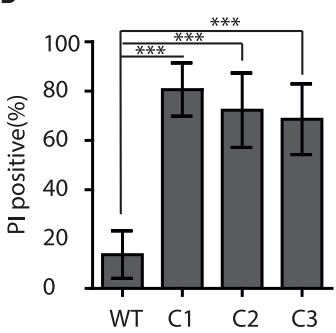

$\mathbf{F}$

N2 (Icmt-/-Tg2)
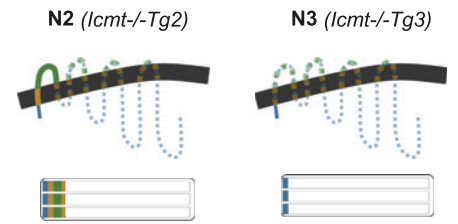$$
\text { . }
$$$$
\text { WT }
$$
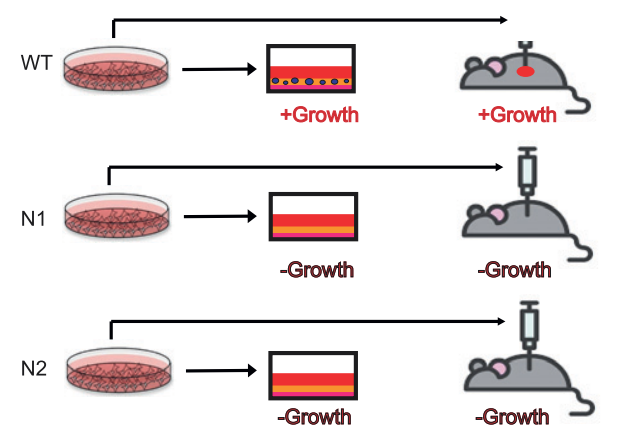

N3
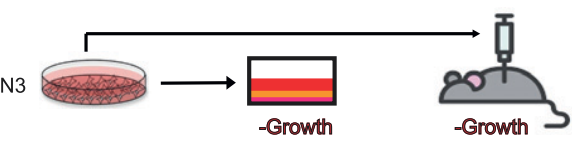

Figure 1. Loss of ICMT abolishes the ability of anchorage-independent growth in vitro and tumor formation of MDA-MB231 breast cancer cells. (A) Schematic illustration of the predicted ICMT polypeptide translated from the genomic DNA sequences in $1 \mathrm{cmt}^{+/+}(W T)$ and predicted residual peptides in the three mixed clones of $1 \mathrm{cmt}^{-/-}$(null) MDAMB231 cells, namely, N1, N2, and N3, generated from three different targeting sequences for the CRISPRCas9 editing, respectively. MDA-MB231 cells have three copies of the I $\mathrm{cmt}$ gene as illustrated in the lower part of panel (A). The blue-, gold-, and green-colored bars represent the cytosolic, endoplasmic reticulum transmembrane, and endoplasmic reticulum luminal regions of ICMT, respectively. The thick and thin dashed lines represent frameshifted nonsense polypeptides and the missing part of ICMT, respectively. The isogenic cell lines were generated by CRISPR/Cas9 gene editing. Each of these cell lines (WT, N1, N2, and N3) is a mixture at the same ratio of three individual clones generated using the same targeting sgRNA (Tg1, Tg2, and Tg3, respectively). (B) Soft agar colony formation assay for $\mathrm{ICmt}^{+/+}$(WT) and $1 \mathrm{cmt}^{-/-}$(N1, N2 and N3) isogenic cell lines. For each cell line, 100,000 cells were seeded in $0.25 \%$ noble agar and cultured for $2-3$ wk before staining by MTS at $0.2 \mathrm{mg} / \mathrm{ml}$. The colonies were then imaged by Olympus SZX16 Research Stereo Microscope; scale bar length $=2 \mathrm{~mm}$. (C) Colonies in (B) were quantified by openCFU and presented using Excel; at least 10 images were analyzed for each condition. “***” $P<0.0005$. The experiment was performed three times with similar results.

(D) Apoptotic cells were quantified using an in-softagar propidium iodide (PI) staining method. The cells of WT, N1, N2, and N3 were seeded in soft agar the same way as in colony formation assay. $3 \mathrm{~d}$ after the seeding, the media above the agar was replaced by $10 \mu \mathrm{g} / \mathrm{ml}$ $\mathrm{PI}$ in PBS and incubated for $30 \mathrm{~min}$, followed by fluorescent imaging for PI using Olympus IX71S1F3 fluorescent Microscope. Total and PI-positive cells were quantified by OpenCFU and analyzed by Prism5; the percentage of PI-positive cells for each condition is presented. “***” $P<0.0005$. The experiment was performed three times with similar results. (E) Tumor

formation ability of $\mathrm{Icmt}^{+/+}$and $\mathrm{Icmt} \mathrm{cos}^{-/-}$isogenic cells in a xenograft model. Top: representative mouse image to show the difference in tumor growth of cells with and without the presence of ICMT; bottom: tumor growth graph of $\mathrm{ICmt}^{+/+}$and I $\mathrm{cmt}^{-1-}$ cells from eight mice. (F) Schematic of the growth phenotypes of $\mathrm{Icmt} \mathrm{C}^{+/+}$and $\mathrm{Icmt}{ }^{-/-}$cells in adherent culture, soft agar colony formation condition and in the in vivo model. Individual black line or red line represents a tumor derived from $/ \mathrm{cmt}^{+/+} \mathrm{cells}$ or $\mathrm{Icmt}^{-1-}$ cells, respectively.

baseline distribution (Fig 2C). This multimodality analysis supports the conclusion that loss of ICMT function leads to aberrant cell cycle progression, particularly notable for G2/M arrest.

\section{ICMT loss of function leads to accumulation of DNA damage and apoptosis, which are the results of impaired DNA damage repair}

One of the major causes of prolonged G2/M arrest and apoptosis in cells is DNA damage, hence we evaluated markers of DNA damage in the $\mathrm{Icmt}^{+/+}$and $\mathrm{Icmt}^{-/-}$cells. Immunoblot analysis on the cells collected from soft agar growth condition showed that, in comparison to the $\mathrm{Icmt}^{+/+}$cells, the $1 \mathrm{cmt}^{-/-}$cells had elevated $\mathrm{p}-\mathrm{yH} 2 \mathrm{AX}$, accompanied by increased cleaved caspase 7 (Fig 3A), which suggested increased DNA damage and the programmed cell death (64). The comet assay is commonly used to measure DNA damage at the single cell level by visualizing the migration of DNA fragments in gel electrophoresis by fluorescence microscopy. The "tail" that trails the nucleus in the fluorescent images can be quantified using
Casplab software (65) (https://casplab.com/download), and the extent of DNA damage is expressed as the "TailMoment" $(66,67)$. In the comparative comet assay study, we found that $\mathrm{Icmt}^{-/-}$cells have significantly bigger TailMoment than the $\mathrm{Icmt}^{+/+}$cells (Fig 3B). We postulated that the apparent increase in DNA damage observed in the $\mathrm{Imt}^{-/-}$cells was either the result of increased DNA damage or of diminished capacity for DNA damage repair. To distinguish between these two causes, we first treated both the $\mathrm{I} \mathrm{cmt}^{+/+}$and $\mathrm{Imt}^{-/-}$cells with zeocin (phleomycin D1), an irradiation mimic agent, to generate DNA damage, followed by a recovery phase in drug-free medium to allow cells to repair the DNA damage. Immunoblot analysis for $\mathrm{p}-\mathrm{yH} 2 \mathrm{AX}$ level was used to follow the repair during the recovering phase. We found that, even though there was no consistent difference in $\mathrm{p}-\gamma \mathrm{H} 2 \mathrm{AX}$ levels between the $\mathrm{Icmt}^{+/+}$and $1 \mathrm{cmt}^{-/-}$cells at the time of zeocin removal, the level of $\mathrm{p}-\mathrm{\gamma H} 2 \mathrm{AX}$ persisted in the $1 \mathrm{cmt}^{-/-}$cells but was reduced rapidly in the $1 \mathrm{cmt}^{+/+}$ cells during recovery, which suggests that loss of ICMT function compromises the cells' ability for DNA damage repair (Fig 3C) (64). 
A

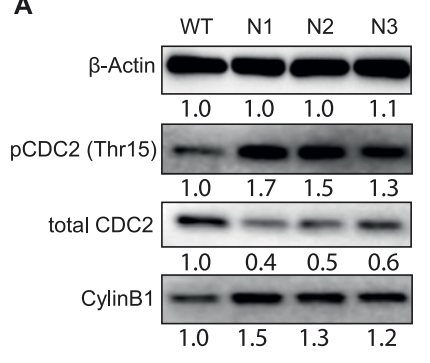

B

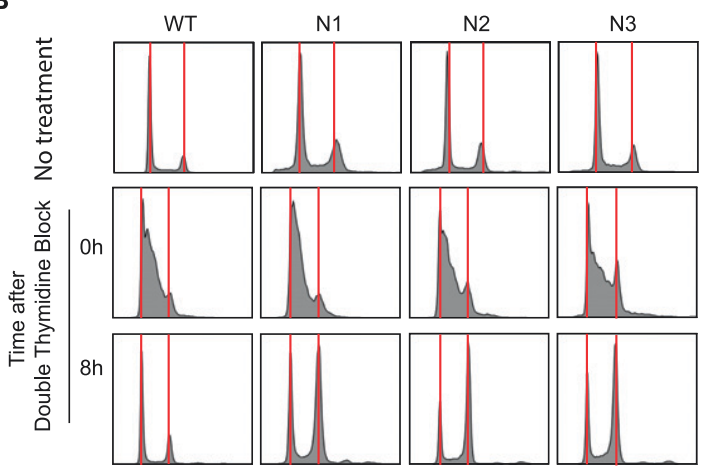

C

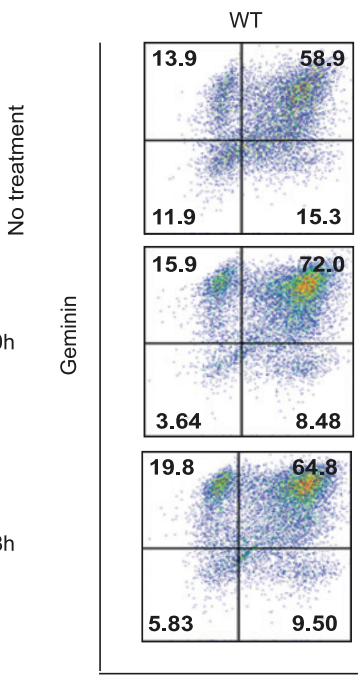

$\mathrm{N} 1$

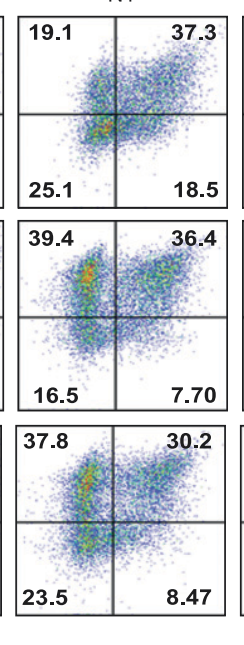

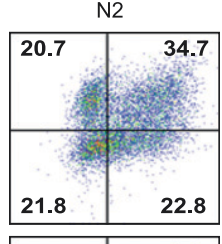

\begin{tabular}{|l|r|}
\hline 29.7 & 50.9 \\
\hline
\end{tabular}
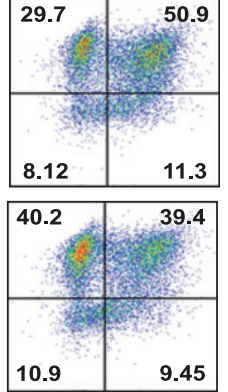

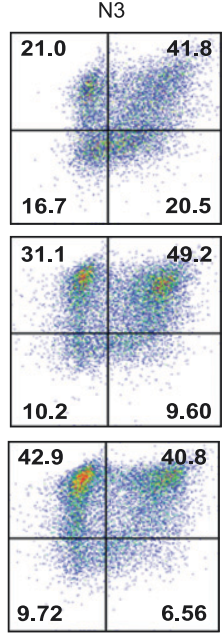

CDT1

Figure 2. Loss of ICMT leads to G2-M cell cycle arrest. (A) Immunoblot analysis for the G2-M cell cycle markers: PCDC2(T15), total-CDC2, and cyclin B1 on the $\mathrm{Imt}^{+/+}$(WT) and $\mathrm{Icmt}^{-/-}$(N1, N2, and N3) isogenic cell lines harvested after growing under standard culture conditions before reach confluency and processed for SDS-PAGE. The numbers below each marker are the densitometry quantification of band intensity. (B) Cell cycle distribution of the isogenic cells in the baseline state without synchronization (top row), and following double thymidine synchronization $(0 \mathrm{~h}$, middle row) and $8 \mathrm{~h}$ post-release (bottom row). The red vertical lines mark the $\mathrm{G} 1$ and $\mathrm{G} 2 / \mathrm{M}$ peaks. The cells were prepared by standard propidium iodide

staining method for cell cycle analysis, as described in the Materials and Methods section. (C) Flow cytometry analysis of Citrine-Geminin and mCherry-Cdt1 in the isogenic cell lines stably expressing these cell cycle markers. Analysis was performed at the baseline state without synchronization (top row), at the time of release from the double thymidine block (middle row, $0 \mathrm{~h}$ ), and $8 \mathrm{~h}$ after release from double thymidine block (bottom row). (B) These cells were subjected to the same preparation conditions as in (B) before standard flow cytometry analysis. The experiments were performed three times with similar findings.
To evaluate whether the role of ICMT in regulating DNA damage repair is limited only to MDA-MB231 cells, we treated several breast cancer cell line with ICMT small molecule inhibitor cysmethynil (49, 68). We found that ICMT inhibitor treatment led to elevated levels of the DNA damage marker $\mathrm{p}-\gamma \mathrm{H}_{2} \mathrm{AX}$ and cleavage of caspase 7 in a range of breast epithelial cancer cells (Fig 3D), consistent with the observation on the MDA-MB231 $\mathrm{lcmt}^{-/-}$cells. These data illustrate that ICMT is involved in the regulation of DNA damage repair in breast epithelial cancer cells with varied genetic background.

In conclusion, multimodality analyses support the notion that loss of ICMT results in defective DNA repair, and that the lingering DNA damage delays cell cycle entry at G2/M check points and leads to apoptotic cell death.

\section{DNA damage repair requires robust MAPK signaling}

The data detailed above suggests that ICMT function is important for the DNA damage repair, cancer cell proliferation, and survival under anchorage-independent growth conditions. PI3K and MAPK signaling are two major oncogenic pathways, which are also downstream of oncogenic RAS. Hence, in the investigation for the mechanism underlying this impact on cancer cells, we studied the role of MAPK and PI3K signaling-in DNA damage repair and in mediating the ICMT regulation of such phenotypes. In the immunoblot analysis of the $\mathrm{Icmt}^{+/+}$and $\mathrm{Icmt}^{-/-}$isogenic cells, we observed that all major components of the MAPK pathway, namely CRAF, MEK, and ERK, had reduced levels of phosphorylation in the $1 \mathrm{cmt}^{-/-}$cells compared with $1 \mathrm{cmt}^{+/+}$cells (Fig 4A) consistent with an earlier observation of the impact of ICMT inhibition on PERK (68), whereas there were less consistent changes in the PAKT levels. However, the PAKT level assessment is limited by its very low expression level for antibody detection.

To further determine the signaling pathway, either MAPK or PI3K/ AKT, which accounts for the differences in the abilities of $1 \mathrm{cmt}^{+/+}$ and $\mathrm{Icmt}^{-/-}$cells to carry out DNA damage repair, we treated MDAMB231 parental cells with escalating concentrations of either the MEK inhibitor PD184352 or the AKT inhibitor Triciribine. We postulated that, $\mathrm{p}-\mathrm{\gamma H} 2 \mathrm{AX}$ would accumulate in a dose-dependent manner in response to a pathway-specific inhibitor if the activation of the pathway is required for the DNA damage repair. Indeed, we found that PD184352 induced dose-dependent reduction of pERK correlated with the increase of $\mathrm{p}-\mathrm{\gamma H} 2 \mathrm{AX}$ and cleaved caspase 7 -markers for persistent DNA damage and the activation of apoptosis (Fig 4B). Phenotypically, PD184352 treatment resulted in dose-dependent reduction of soft agar colony formation (Fig 4 C and D). In contrast, Triciribine inhibition of PAKT, the major PI3K downstream effector, was associated with neither changes of $\mathrm{p}-\mathrm{yH} 2 \mathrm{AX}$ or cleaved caspase 7 markers (Fig 4E), nor that of soft agar colony formation ability (Fig 
A

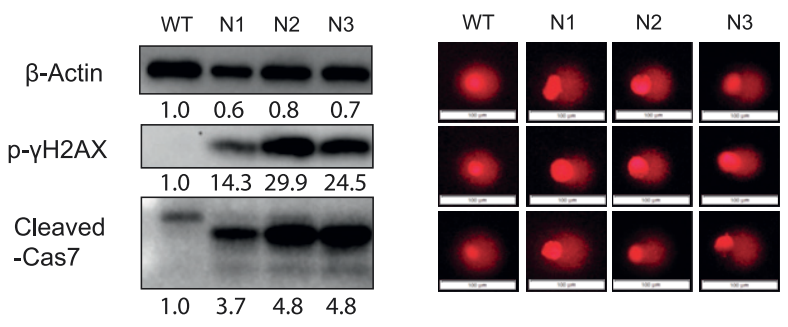

C

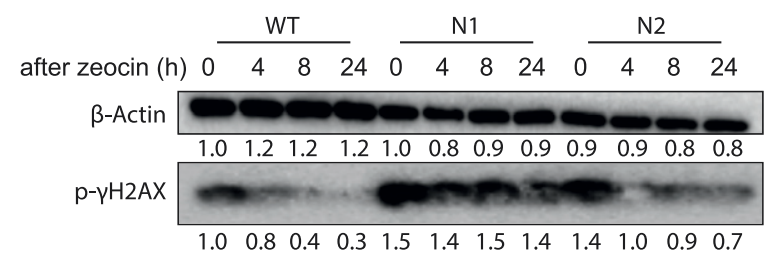

D

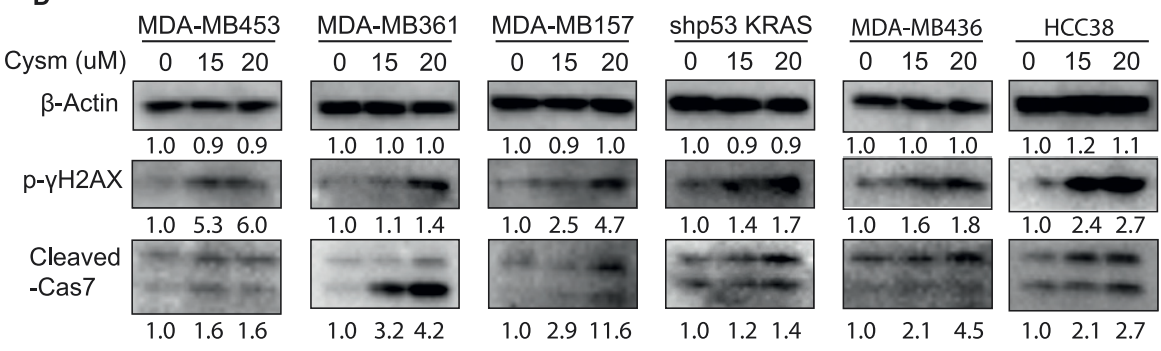

Figure 3. Loss of ICMT results in the accumulation of DNA damage.

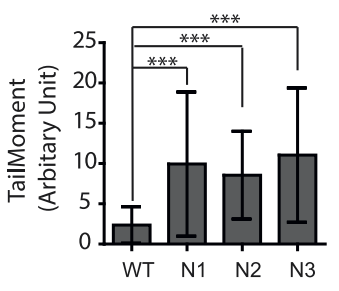

(A) Immunoblot analysis of DNA damage and apoptosis marker proteins in $\mathrm{I} \mathrm{cmt}^{+/+}$(WT) and $\mathrm{Icmt}^{-/-}$(N1, N2 and N3) isogenic cell lines. Lysates were prepared from cells seeded in soft agar culture and grown for $3 \mathrm{~d}$; the preparation method is described in detail recently (104). (B) Comet assay for DNA damage in the isogenic cell lines. Cells were cultured in low attachment plates for $3 \mathrm{~d}$ before prepared for the comet assay detailed in the Materials and Methods section (67). DNA in the cells was visualized by propidium iodide staining and imaged by Olympus IX71S1F3 fluorescent microscope; three representative cells are shown for each isogenic cell line (top panel). Scale bar length $=100 \mu \mathrm{m}$. The right side of the panel shows the result of analysis of more than 100 cells for each cell line using the Casplab (https://casplab.com/download) software to calculate the TailMoments, which quantify the extent of DNA damage. "***” $P<0.001$. The study was repeated with similar results. (C) Immunoblot analysis of lysates from the isogenic cell lines for the DNA damage marker $\mathrm{p}-\mathrm{\gamma H}_{2} \mathrm{AX}$. Cells grown in normal culture were treated with $1 \mu \mathrm{g} / \mathrm{ml}$ zeocin for $48 \mathrm{~h}$, followed by recovery in fresh drug-free medium for $0,4,8$, and $24 \mathrm{~h}$ before lysed and prepared for SDS-PAGE and immunoblot analysis for the indicated proteins. (D) Immunoblot analysis on several breast cancer cell lines to study the impact of ICMT inhibitor treatment on DNA damage and apoptosis. For all immunoblots, the numbers below each marker are the densitometry quantification of band intensity.
$4 F$ and $G$ ). The differences between the cell responses to MEK inhibitor and ATK inhibitor treatment support the notion that the MAPK, not the PI3K/AKT signaling, plays a functionally important role in DNA damage repair in the breast cancer cells. Finally, the effect of MEK inhibitor on DNA damage was visualized by comet assay in MDA-MB231 cells. Consistent with the changes in $\mathrm{p}-\mathrm{yH} 2 \mathrm{AX}$, the TaillMoment (Fig $4 \mathrm{H}$ ) calculated from the fluorescent single cell DNA fragmentation imaging (Fig 4I) increased in a PD184352 dosedependent manner, confirming the importance of ERK activity in DNA damage repair and survival of MDA-MB231 cells.

The pathway-specific inhibitor treatment data support the conclusion that reduction of ERK activity compromises the ability of breast cancer cells to repair DNA damage, which is the likely mechanism for the accumulation of the damage and cell cycle arrest in $\mathrm{Icmt}^{-/-}$cells. To further distinguish the roles of MAPK and PI3K signaling in DNA damage repair, we performed rescue experiments by increasing pathway-specific signaling via the expression of either constitutively active CRAF (RAF22W) or p110-CAAX in $1 \mathrm{cmt}^{-/-}$cells, and evaluated the impact on DNA damage, cell cycle progression, apoptosis, and colony formation ability. First, we found that expression of $\mathrm{CRaf}-22 \mathrm{~W}$ significantly reduced apoptosis in $\mathrm{Imt}^{-/-}$cells cultured in soft agar (Fig 5A), and restored their colony formation ability (Fig 5B and C). To investigate whether expression of CRAF-22W enhanced DNA damage repair, we subjected the $1 \mathrm{cmt}^{+/+}$ and $1 \mathrm{cmt}^{-/-}$cells, with and without exogenous expression of CRAF$22 \mathrm{~W}$, to treatment with low dose zeocin for $48 \mathrm{~h}$ followed by $24 \mathrm{~h}$ of release and determined the efficiency of DNA repair. In this setting, we observed that successful restoration of pERK in $\mathrm{Imt}^{-/-}$cells by expressing CRAF-22W is accompanied by the reduction of zeocininduced $p-\gamma \mathrm{H} 2 \mathrm{AX}$ (Fig 5D). We also performed the comet assay to study the ability of CRAF-22W to rescue DNA damage repair in $/ \mathrm{cmt}^{-/-}$ cells cultured in suspension. Consistent with the other rescue results, the comet assay showed that expression of CRAF-22W reduced the TailMoment of $/ \mathrm{cmt}^{-/-}$cells to similar levels to those of the $1 \mathrm{cmt}^{+/+}$ cells grown in suspension (Fig $5 \mathrm{E}$ and F), which is consistent with the notion that MAPK signaling is essential for DNA damage repair capability. Immunoblot analysis on the same cells used for comet assay demonstrated that cRaf-22W expression and accompanying increased levels of activated MEK and ERK led to significant reduction of $p-\gamma \mathrm{H} 2 \mathrm{AX}$ and cleaved caspase 7 (Fig 5G).

We next compared the effect of RAF22W and p110-CAAX overexpressing in restoring the soft agar colony formation ability of stable ICMT knockdown cells; we found that only the expression of RAF22W but not p110-CAAX restored the colony forming ability in ICMT knockdown cells (Fig $5 \mathrm{H}$ and I). Consistently, the immunoblot evaluation demonstrated that whereas both p110 and RAF22W sufficiently activated their downstream effectors-PAKT and pMEK, respectively, only RAF22W reduced the $p-\gamma \mathrm{H}_{2} \mathrm{AX}$ and cleaved caspase 7 (Fig 5J). Worth noting, the ICMT knockdown cells instead of knockout cells were used here for the comparison of RAF22W and p110 overexpression effect, as we have observed significant toxicity of expressing p110 in the Icmt ${ }^{-/-}$ cells that was limiting their colony formation ability.

In summary, the studies of manipulating MAPK signaling in either direction using control and ICMT suppressing MDA-MB231 cells provide convincing evidence to support the importance of ERK activation in the repair of DNA damage, caused by either irradiation 
A

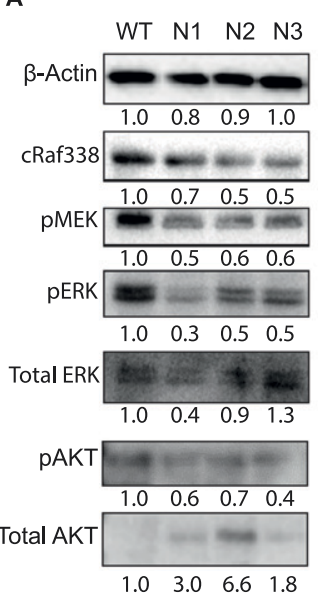

E

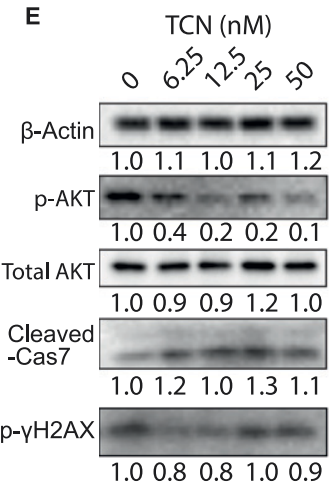

H

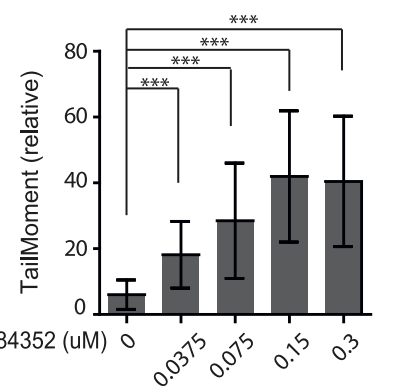

B

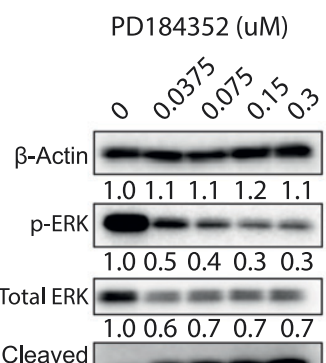

Cleaved $-\infty$
-Cas7

$\begin{array}{lllll}1.0 & 1.5 & 1.8 & 2.0 & 2.2\end{array}$

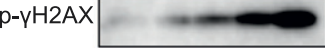

1.02 .03 .86 .38 .7
C

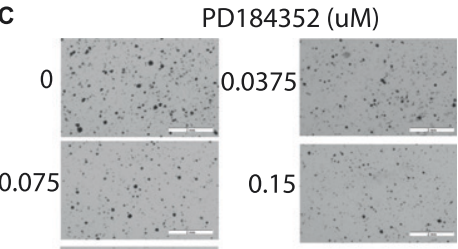

0.3
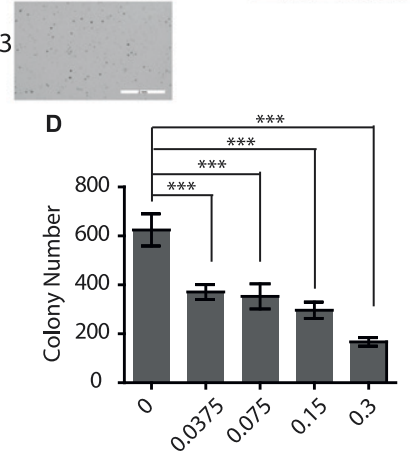

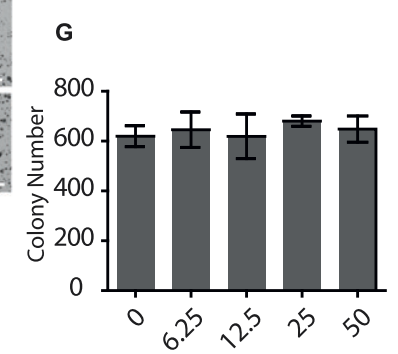

I
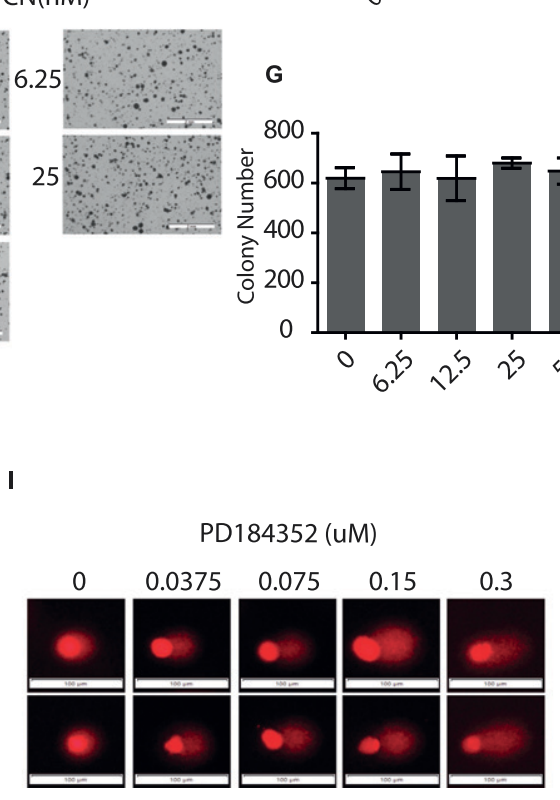

(u)

D184352 (uM)
Figure 4. Maintenance of a robust MAPK signaling is necessary for DNA damage repair in MDA-MB231 breast cancer cells.

(A) Immunoblot for the MAPK pathway proteins-pRAF, PMEK, and PERK - and PI3K downstream proteins pAKT and AKT in the lysates of $/ \mathrm{cmt}^{+/+}(\mathrm{WT})$ and $\mathrm{Icmt}^{-/-}$ (N1, N2, and N3) isogenic cell lines. (B) Immunoblot analysis of MAPK activation, DNA damage, and apoptosis in the lysates of MDA-MB231 parental cells grown in the soft agar under the treatment of PD184352, a MEK inhibitor, at the indicated concentrations. (C, D) Soft agar colony formation on MDA-MB231 cells treated with different concentrations of PD184352. The scale bar length $=2 \mathrm{~mm}$ in the images.

(D) Quantification of the colonies in (C) using OpenCFU and Prism5 software. “***" $P<0.0001$. (E) Immunoblot analysis of AKT activation, DNA damage, and apoptosis in the lysates of MDA-MB231 parental cells grown in the soft agar under the treatment of Triciribine, an AKT inhibitor, at the indicated concentrations. (F, G) Soft agar colony formation on MDA-MB231 cells treated with different concentrations of Triciribine. The scale bar length $=2 \mathrm{~mm}$ in the images.

(G) Quantification of the colonies in (F) using OpenCFU and Prism5 software. There are no statistical differences among different treatment conditions. $(\mathbf{H}, \mathbf{I})$ Comet assay for DNA damage in response to MEK inhibitor treatment. MDA-MB231 cells were treated with PD184352 at the indicated concentrations for $48 \mathrm{~h}$ under normal culture condition before seeding for comet assay. The TailMoment (D) were calculated using Casplab software based on the analysis of more than 100 cells for each PD184352 concentration-two representative images for each condition are shown in (E). See the Materials and Methods section for details. “***" $P<0.001$. The study was repeated with similar results. The scale bar length $=100 \mu \mathrm{m}$ in the images. For all immunoblots, the numbers below each marker are the densitometry quantification of band intensity. mimic agent zeocin or by anchorage-independent growth conditions. More importantly, these data establish that loss of Icmt compromise the cell machinery of DNA damage repair by suppressing the activity level of the MAPK signaling pathway.

\section{ICMT regulates the expression of key DNA damage repair pathway genes mediated through MAPK pathway}

We next evaluated the potential impact of ICMT on the DNA damage repair machinery. To this end, we assessed the transcription of several key proteins that are involved in various processes in DNA damage repair, including nucleotide excision, $\mathrm{HR}$, non-homologues end joining, and single-strand break repair $(19,20,69,70,71,72,73$, $74,75,76,77,78,79,80,81,82,83,84)$. Expression analysis revealed that $/ \mathrm{cmt}^{-/-}$cells express significantly less of several key DNA repair genes compared with $\mathrm{Icmt}^{+/+}$cells (Fig 6A). Consistent with the notion that MAPK signaling is the critical downstream mediator for this ICMT function, MEK inhibitor treatment similarly reduced the expression of the same genes in a dose-dependent manner (Fig 6B). In contrast, AKT inhibitor treatment did not result in similar gene expression changes, providing further evidence that AKT does not play a similar role in DNA damage repair in MDA-MB231 cells (Fig 6C). Further validating the role of ICMT in the regulation of the expression of these genes, we subjected multiple breast cancer cell lines to ICMT inhibitor treatment. Importantly, pharmacological inhibition of ICMT in multiple breast cancer cells resulted in a dosedependent reduction of expression of the same panel of genes (Fig $6 D$ ). Finally, we assessed the impact of introduction of RAF22W on the expression of these DNA damage repair genes, which demonstrated consistently that activation of MAPK signaling via this 
A

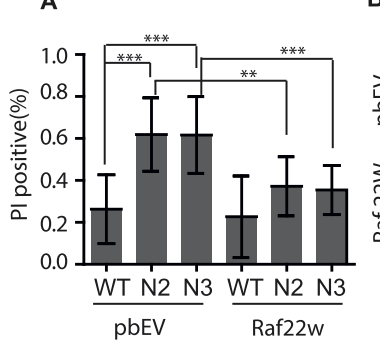

D Recovery from Zeocin treatment

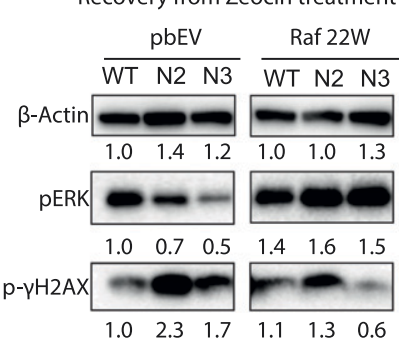

G
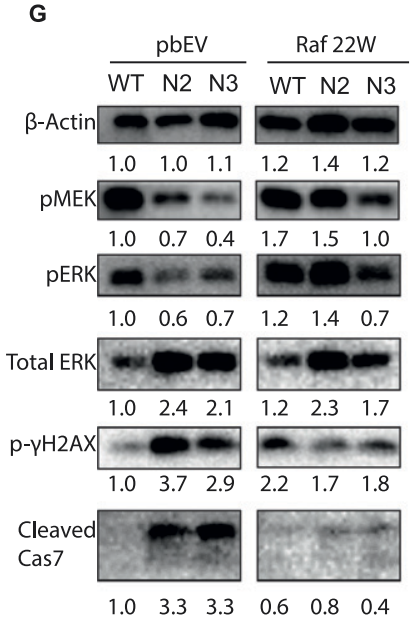

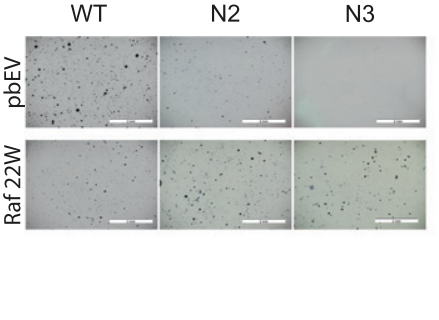

E

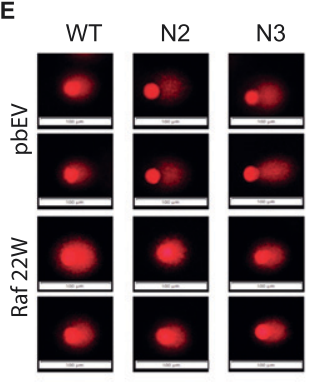

H
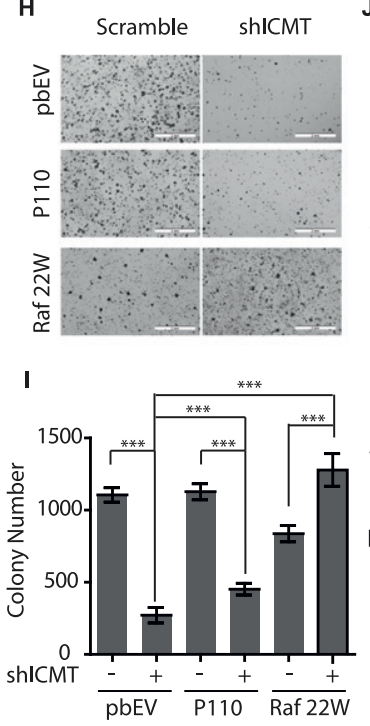

C

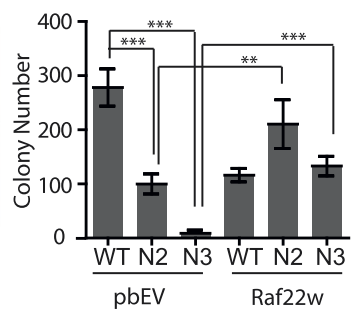

$\mathbf{F}$
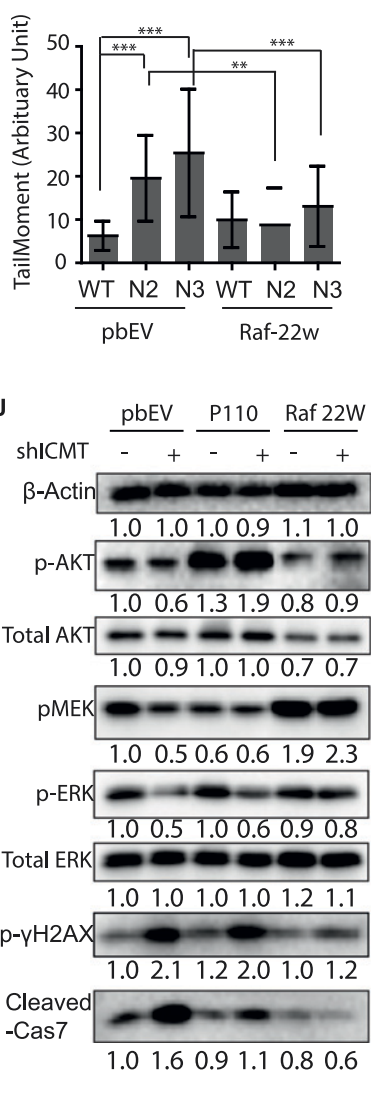

Figure 5. Expression of constitutively active CRAF reduces DNA damage and apoptosis in the $1 \mathrm{cmt}^{-/-}$ cells, and restores their ability to grow in soft agar. (A) Propidium iodide staining and quantification for apoptotic cells among the $\mathrm{Imt}^{+/+}$(WT) and $1 \mathrm{Cmt}^{-/-}$ isogenic cells seeded in soft agar with and without the expression of RAF-22W, an activated form of CRAF. (B, C) Soft agar colony formation of the isogenic cells with and without the exogenous expression of RAF22W. (B) Light microscopic images of the colonies, which were quantified in (C) using OpenCFU and Prism5 software. "**" $P<0.001 ;$ " “***" $P<0.0001$. The scale bar length $=2 \mathrm{~mm}$ in the images. (D) Immunoblot analysis of $p E R K$ and $p-\gamma H 2 A X$ in lysate of the isogenic cells with and without the exogenous expression of RAF-22W; the cells were pretreated with zeocin for $48 \mathrm{~h}$ followed by recovery in drug-free medium for $24 \mathrm{~h}$. (E) Comet DNA damage assay of the isogenic cell lines with and without exogenous expression of RAF-22W. Cells were grown in suspension culture for $48 \mathrm{~h}$ before subjected the standard comet assay as described in the Materials and Methods section. Two representative images of cells in each group are shown; the scale bar length $=100 \mu \mathrm{m}$ in the images. (F) Data analysis and quantification for Tailmoments of the study shown in (E); 100 cells were analyzed for each group of cells. ${ }^{\prime * \star *} P<0.01 ;$; ${ }^{* \star \star * "} P<0.001$. The experiment was performed three times with similar results. (G) Immunoblot analysis of MAPK signaling components, DNA damage and apoptosis markers in the isogenic cells grown in soft agar, with and without the exogenous expression of RAF-22W. Protein extraction from cells grown in soft agar is describe in detail in the Materials and Methods section. $(\mathbf{H}, \mathbf{I})$ Soft agar colony formation of MDA-MB231 cells stably expressing control shRNA or ICMT-targeting shRNA, with and without the exogenous expression of p110CAAX or RAF-22W. (H) Light microscopic images of the colonies, which were quantified in (I) using OpenCFU and Prism5 software. "***"P<0.0001. The scale bar length $=2 \mathrm{~mm}$ in the images. $(\mathbf{H}, \mathbf{l}, \mathbf{J})$ Immunoblot analysis of markers for MAPK and AKT signaling, DNA damage and apoptosis in cells described in $(\mathrm{H}, \mathrm{I})$ grown in soft agar. Protein extraction from cells grown in soft agar is describe in detail in the Materials and Methods section. For all immunoblots, the numbers below each marker are the densitometry quantification of band intensity relative to the control. route significantly increased the expression of several of the DNA damage repair genes (Fig S2), consistent with the results of MEK inhibitor treatment.

\section{Suppression of ICMT sensitizes breast cancer cells to PARP inhibitor-induced DNA damage and reduces their ability to form xenograft tumors}

DNA damage occurs frequently in both benign and malignant cells. DNA damage triggers cell cycle check points and, ultimately, the programmed cell death pathway. PARP1 is involved in many aspects of DNA damage repair response, and has been particularly linked to the process of repair of single-strand DNA breaks (85); when PARP1 is inhibited, DNA damage accumulates (86). BRCA family of proteins are well-known for their roles in the homologous recombination repair pathway (87). BRCA loss-of-function mutations are predisposition factors for the development of breast and ovarian cancers (88). Indeed, cancers that carry BRCA mutations are more vulnerable, compared to the BRCA wild-type cancers, to PARP inhibitors because of their reduced ability to repair DNA damage.

MDA-MB231 is among the breast cancer cell lines that are considered resistant to PARP inhibitor treatment (89). To further explore the notion that ICMT function is essential in supporting ERK-dependent DNA damage repair and the potential application in cancer treatment, we evaluated the effect of concurrent suppression of PARP1 and ICMT. We postulated that, based on current evidence, suppression of ICMT would render the usually resistant MDA-MB231 cells into a "BRCA-like" state, hence vulnerable to the treatment with PARP inhibitor. To this end, we treated $1 \mathrm{cmt}^{+/+}$and $1 \mathrm{cmt}^{-/-}$cells with either vehicle control or the PARP1 inhibitor niraparib for $48 \mathrm{~h}$, followed by immunoblot assessment of the levels of $\mathrm{p}-\mathrm{\gamma H} 2 \mathrm{AX}$ and cleaved caspase 7 for DNA damage and apoptosis. 
A

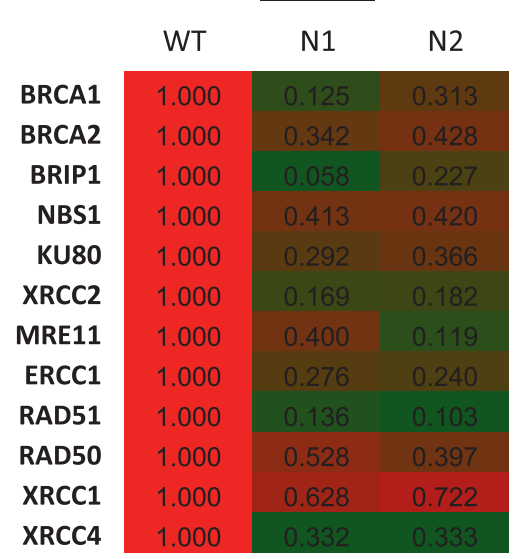

D

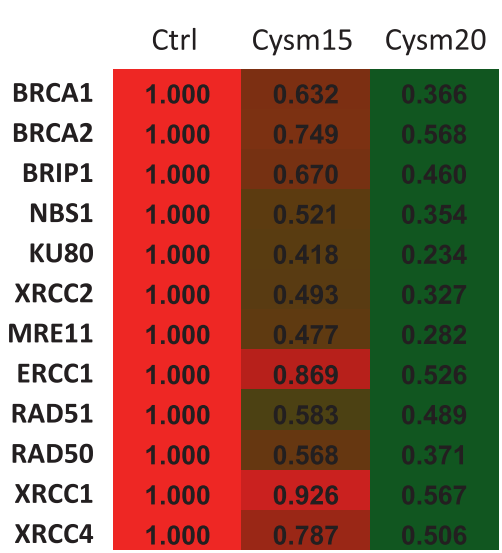

B

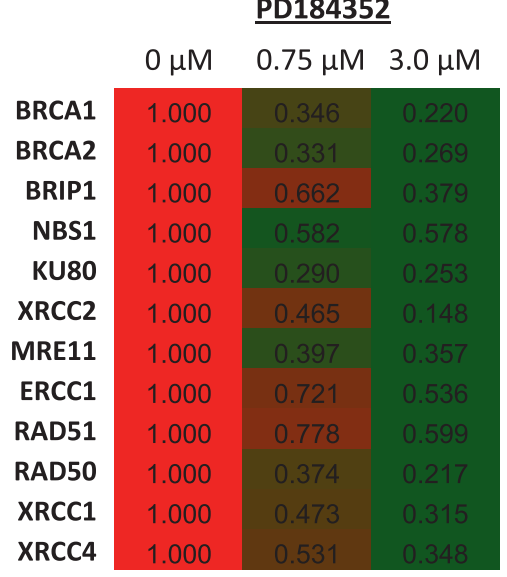

MDA-MB361

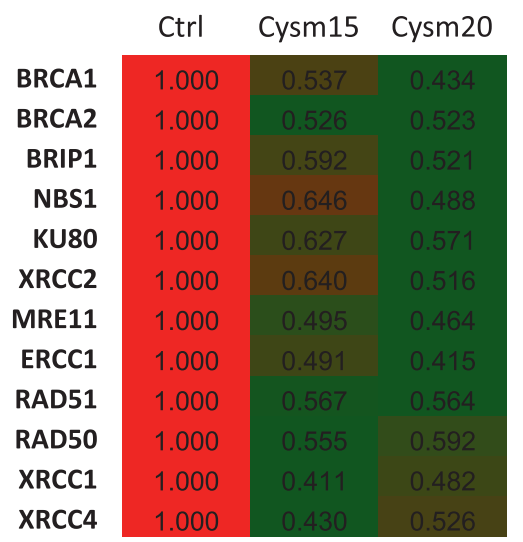

C
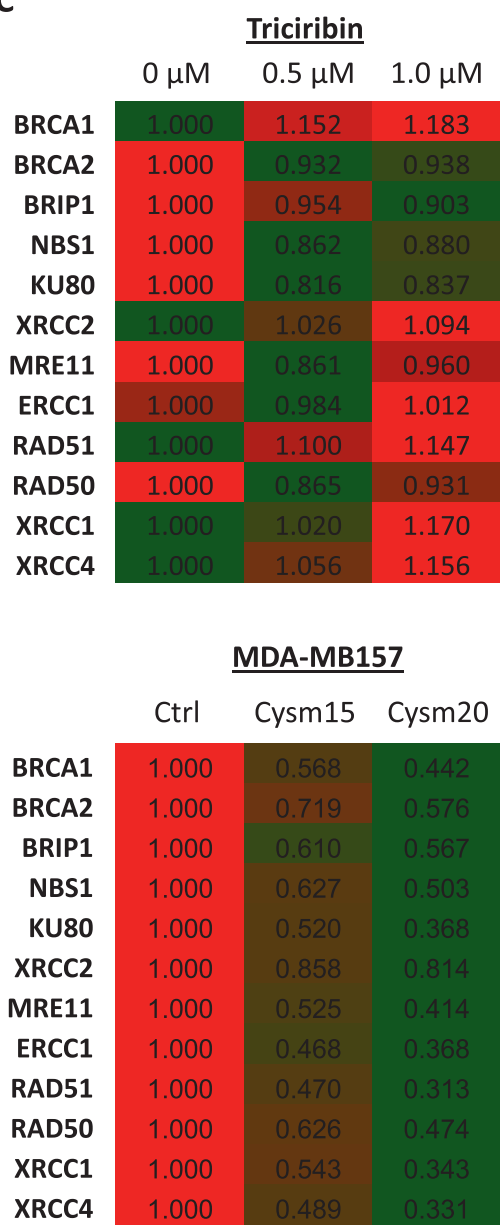

Figure 6. ICMT regulates the expression of multiple DNA damage repair genes through the regulation of MAPK signaling.

(A) qPCR analysis of a panel of DNA damage repair genes in Icmt ${ }^{+/+}$(WT) and Icmt ${ }^{-/-}$(N2 and N3 mixed clones) MDA-MB231 cells. (B, C) Q-PCR analysis of the same panel of genes in MDA-MB231 cells treated with either vehicle control or two different concentrations of either PD184352 MEK inhibitor or Triciribine AKT inhibitor. (D) Q-PCR analysis of the same panel of genes in three different breast cancer cell lines after subjecting to either vehicle control or the indicated concentrations of cysmethynil ICMT inhibitor treatment.

We found that these markers only slightly elevated in the $1 \mathrm{cmt}^{+/+}$ MDA-MB231 cells in response to niraparib treatment (Fig 7A). Consistent with the sluggish marker response, niraparib treatment had little effect on cell proliferation or survival, as assessed by cell viability assay, on multiple breast cancer cell lines (Fig S3). In the $\mathrm{ICmt}^{-/-}$cells, however, the baseline levels of $\mathrm{p}-\mathrm{yH} 2 \mathrm{AX}$ and cleaved caspase 7, which were higher than $1 \mathrm{cmt}^{+/+}$cells, were further elevated in response to niraparib treatment (Fig 7A). Next, we assessed the role of ERK activity in mediating the combination effect of ICMT and PARP suppression by co-treatment of the $\mathrm{Icmt}{ }^{+/+}$cells with MEK and PARP inhibitors. Here, we found that inhibition of MEK or PARP1 alone resulted in only slight elevation of $\mathrm{p}-\mathrm{\gamma H} 2 \mathrm{AX}$, whereas the combination of low dose of MEK inhibitor with $5 \mu \mathrm{M}$ of niraparib led to massive elevation of $\mathrm{p}-\mathrm{y} \mathrm{H} 2 \mathrm{AX}$ (Fig 7B). Noteworthy, the reduction of pERK under MEK inhibitor treatment is at similar level with and without niraparib, consistent with the understanding that the two inhibitors work by independent mechanisms. This combination study not only supports the role of ERK activity in ICMT regulation of DNA damage repair activity, but also demonstrates clearly that combined inhibition of MAPK pathway and PARP1 function can be potentially useful in the treatment of this group of cancers.

We further investigated the combination effect of PARP inhibition and ICMT suppression in in vivo models of tumor growth. The extent of suppression for individual target, that is, ICMT and PARP, was kept at moderate level, so as to allow potential synergy to be readily observable. To achieve moderate inhibition of ICMT, ICMT stable knockdown cells instead of knockout cells were used in the combination study. To this end, MDA-MB231 cells that express either control shRNA or ICMT-targeting shRNA were implanted in the flanks of SCID mice; the mice in each group were divided into vehicle or niraparib treatment sub-groups. Niraparib treatment at $80 \mathrm{mg} / \mathrm{kg} /$ day was initiated when the tumors had achieved the average sizes of 150-250 $\mathrm{mm}^{3}$ for all groups (Fig S4A). Tumor growth was monitored throughout the niraparib treatment course until the end of experiment, which was determined as when the fastest growing group of tumors reached the average size of $1.5 \mathrm{~cm}^{3}$ as required by IACUC protocol. RT-PCR validation of ICMT expression levels in the isolated tumors demonstrated that the ICMT level was 
A

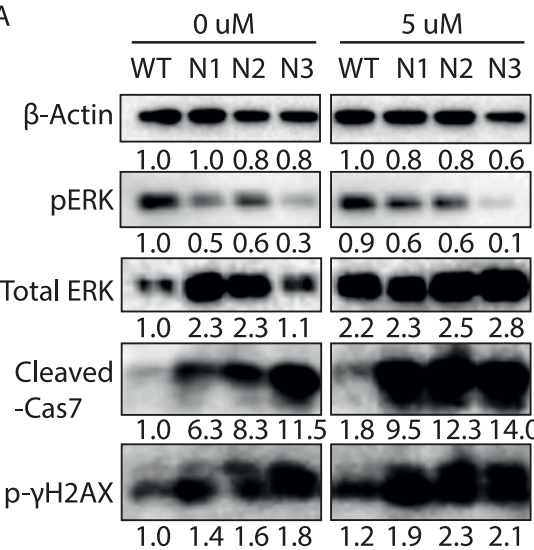

$\mathrm{C}$

$E$
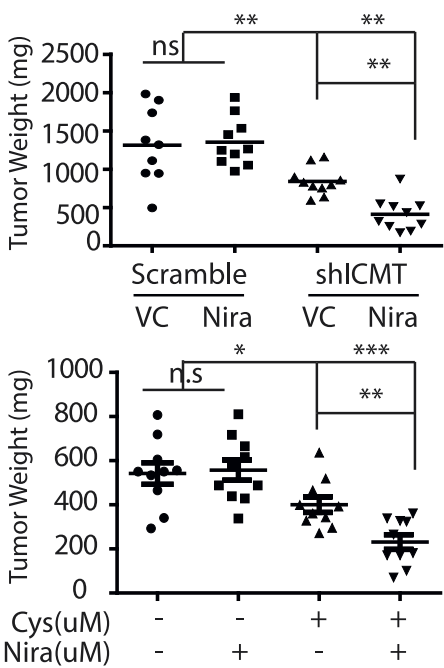

F

D

G

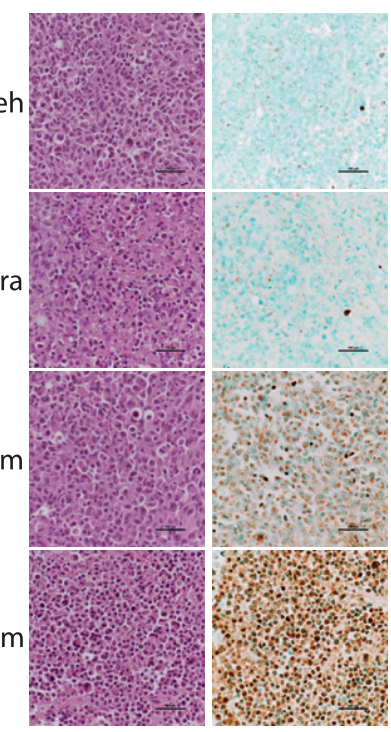
B

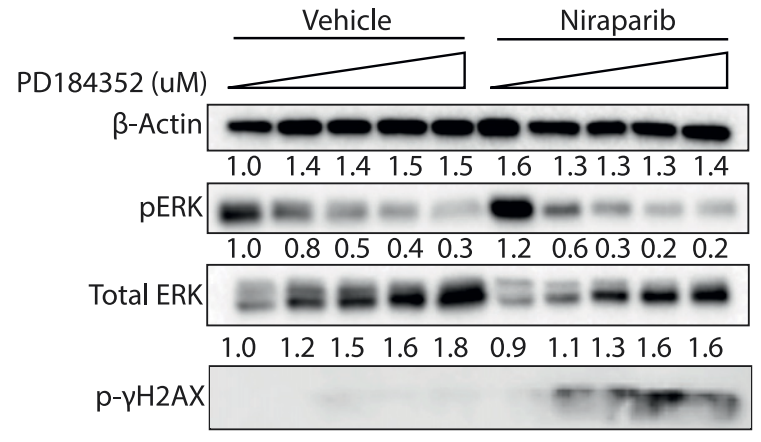

$\begin{array}{lllllll}1.0 & 0.6 & 8.6 & 2.2 & 6.3 & 13.3 & 65.874 .783 .172 .5\end{array}$

D

Scramble

shICMT
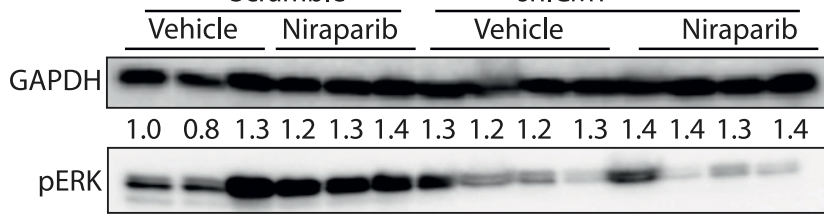

$\begin{array}{lllllllllllllll}1.0 & 1.1 & 2.2 & 1.9 & 1.7 & 1.7 & 1.2 & 0.7 & 0.6 & 0.3 & 1.0 & 0.2 & 0.3 & 0.2\end{array}$

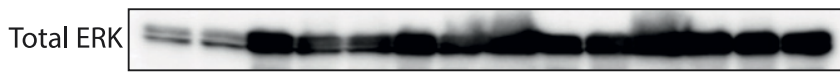

$\begin{array}{llllllllllllll}1.0 & 1.7 & 3.6 & 3.1 & 3.0 & 4.6 & 4.1 & 4.9 & 4.5 & 4.0 & 5.2 & 5.0 & 4.5 & 3.9\end{array}$

$p-\gamma H 2 A X$

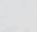

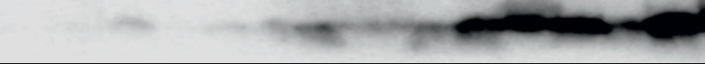

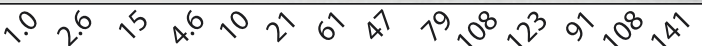

Cleaved

Cas7

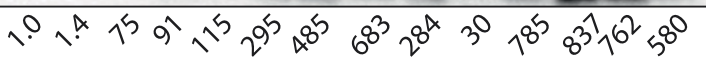

MDA-MB157

MDA-MB361

$\begin{array}{lllllllllllllll}\text { Cys(uM) } & 0 & 15 & 20 & 15 & 20 & 15 & 20 & 0 & 15 & 20 & 15 & 20 & 15 & 20\end{array}$

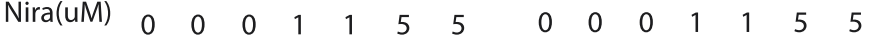

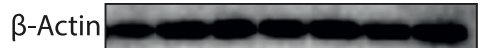

$\begin{array}{llllllll}1.0 & 1.2 & 1.2 & 1.0 & 1.0 & 1.1 & 1.1\end{array}$
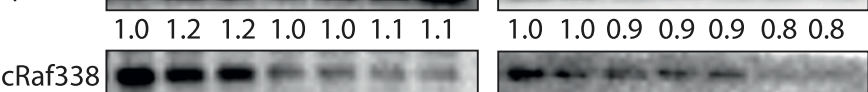

$\begin{array}{lllllllllllllll}1.0 & 0.8 & 0.6 & 0.2 & 0.3 & 0.3 & 0.3 & 1.0 & 0.8 & 0.7 & 0.5 & 0.5 & 0.3 & 0.4\end{array}$

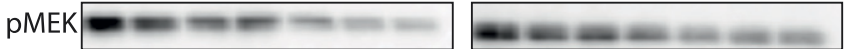

$\begin{array}{lllllllllllllll}1.0 & 0.7 & 0.6 & 0.6 & 0.3 & 0.3 & 0.2 & 1.0 & 0.7 & 0.7 & 0.6 & 0.4 & 0.4 & 0.4\end{array}$

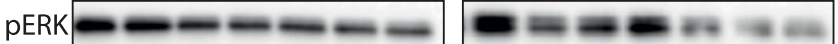

$\begin{array}{llllllllllllll}1.0 & 0.9 & 0.7 & 0.7 & 0.7 & 0.6 & 0.6 & 1.0 & 0.6 & 0.7 & 0.8 & 0.4 & 0.3 & 0.3\end{array}$
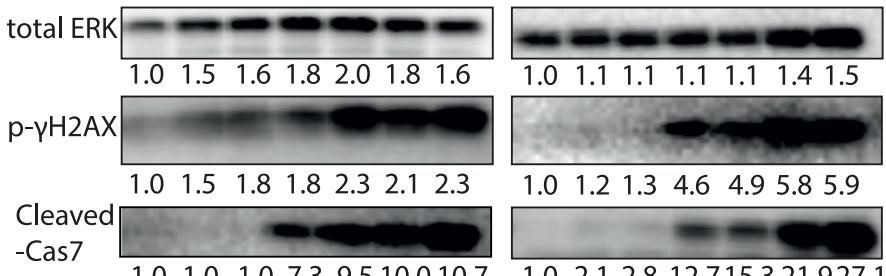

-Cas7 $\begin{array}{lllllllllllll}1.0 & 1.0 & 1.0 & 7.3 & 9.5 & 10.0 & 10.7 & 1.0 & 2.1 & 2.8 & 12.715 .321 .927 .1\end{array}$

Figure 7. Concurrent suppression of ICMT and PARP1 is synergistic in eliciting DNA damage, inducing apoptosis and inhibiting tumor growth for MDA-MB231 breast cancer cells.

(A) Immunoblot analysis of pERK markers, $\mathrm{p}-\gamma \mathrm{H} 2 \mathrm{AX}$, and cleaved caspase 7 in the lysates of $\mathrm{Icmt} \mathrm{ct/}^{++}(\mathrm{WT})$ and $\mathrm{Icmt} \mathrm{C}^{-/-}$(N1, N2 and N3) isogenic cells treated with either vehicle control or $5 \mu \mathrm{M}$ of niraparib $48 \mathrm{~h}$ under the standard culture condition. (B) Immunoblot analysis on the lysates of parental MDA-MB231 cells treated with either MEK inhibitor alone, or combination of the MEK inhibitor with $5 \mu \mathrm{M}$ niraparib. Cells were pre-treated with MEK inhibitor PD184352 at the indicated concentration for $24 \mathrm{~h}$, followed by the co-treatment with $5 \mu \mathrm{M}$ niraparib for another $48 \mathrm{~h}$, before lysate preparation for SDS-PAGE and immunoblot of the indicated proteins. (C) Xenograft tumor growth of implanted MDA-MB231 cells with and without ICMT knockdown, under either vehicle or niraparib treatment. Fifteen million cells expressing either control shRNA 
maintained $60-70 \%$ of the control samples, which was desirable for the combination study; and there is no significant difference of ICMT expression between the vehicle and the niraparib treatment groups (Fig S4B). Analysis of tumor size showed that, despite being statistically indistinguishable among the four groups before the initiation of niraparib treatment (Fig S4A), the sizes of the tumors derived from ICMT knockdown cells were significantly smaller than those from control shRNA expressing cells at the end point (Figs 7C and $\mathrm{S} 4 \mathrm{C}$ ). More importantly, niraparib treatment further reduced the sizes of tumors derived from ICMT knockdown cells, whereas the same treatment had no effect on the tumors derived from cells expressing control shRNA (Figs $7 C$ and S4C and D). The resistance to niraparib is expected because MDA-MB231 breast cancer cells are considered BRCA wild type, or in a broad and precise term, to have no deficiency in DNA damage repair machinery. As anticipated, immunoblot analysis on the tumor samples showed that niraparib treatment induced slight increase of $\mathrm{p}-\mathrm{\gamma H} 2 \mathrm{AX}$ and cleaved caspase 7 in control tumors, whereas the same treatment led to massive elevation of these markers in the tumors derived from ICMT knockdown cells (Fig 7D). It is interesting to note that ICMT knockdown alone induced significant level of $\mathrm{p}-\mathrm{\gamma H} 2 \mathrm{AX}$ and cleaved caspase 7, and reduced PERK consistent with the in vitro observations (Fig 7D). So far, the in vivo ICMT inhibition has been achieved by shRNA knockdown. However, it is important to evaluate whether pharmacological inhibition of ICMT has the same effect for potential future therapeutic considerations. To this end, we performed the similarly designed in vivo tumor growth inhibition study using ICMT small molecule inhibitor and niraparib. We observed consistent tumor growth inhibition patterns for vehicle control, either inhibitor alone and combination treatment, as that from the ICMT knockdown and niraparib combination study (Figs $7 E$ and $\mathrm{S} 5 \mathrm{~A}-\mathrm{C}$ ). Furthermore, we performed TUNEL assay using the isolated tumors to study the effect of drug treatment on apoptosis. Consistent with the tumor growth pattern of the four groups, TUNEL assay showed that niraparib induced no changes in apoptosis, whereas cysmethynil and combination treatment induced significantly higher and massive levels of apoptosis, respectively (Figs 7F and S5D). Together, the in vitro and in vivo evidence lead us to conclude that ICMT suppression in breast cancer cells creates a "BRCA-like" state, hence sensitizing them to PARP1 inhibitorinduced growth inhibition and apoptosis.

Finally, we expanded the synthetic lethality study of ICMT and PARP1 inhibition to other breast cancer cells. To this end, we subjected additional breast cancer cell lines to cysmethynil or niraparib or combination treatment. We observed that cysmethynil treatment, similar to genetic knockdown of ICMT, reduced ERK activation; and the combination of cysmethynil and niraparib resulted in robust DNA damage and apoptosis (Fig 7G).

\section{Discussion}

A role for ICMT in regulating DNA damage repair has not been previously recognized, despite multiple reports of cell cycle arrest associated with ICMT inhibition $(48,90)$. In this study, we observed significant increase of $\mathrm{G} 2 / \mathrm{M}$ population in the $\mathrm{Icmt}^{-/-}$MDA-MB231 cells compared with the parental cells, leading us to examine the process of DNA damage and repair. We first evaluated whether ICMT directly affects $G 2 / M$ check point proteins to cause the arrest or DNA damage accumulation leads to secondary G2/M arrest. CDC25 proteins are critical components of the $\mathrm{G} 2 / \mathrm{M}$ check point and had been introduced in MDA-MB231 cancer cells to reverse G2/M arrest and rescue cell death in various studies $(91,92)$. To investigate whether loss of ICMT function directly impacts the G2/M check point, we overexpressed the functionally important CDC25A in the $\mathrm{ICmt}^{-/-}$cells to evaluate the rescue effects. We observed that although CDC25A overexpression significantly reduced the population of cells in G2/M (Fig S6A), the ability of the I cmt null cells to form colonies in the soft agar was not at all affected (Fig S6B), suggesting that the $\mathrm{G} 2 / \mathrm{M}$ arrest is not the root cause for cell death and loss of anchorage-independent growth for the Icmt null cells. In other word, simply forcing Icmt null cells to pass the check point would not rectify the consequence from the loss of ICMT function.

DNA damage is one of the major triggers for cell cycle arrest (93). It is understood that halting of proliferation in the presence of DNA damage is necessary for multicellular organisms to maintain genetic integrity. DNA damages can be induced by many physical, chemical and biological factors, most notably radiation, drugs/ toxins and replicative stress $(4,5,53,94,95)$ (Fig 8A). Many cancer cells have sufficient DNA damage repair function that preserves their survival and proliferative ability; however, acute increase in DNA damage or reduction of the capacity for repair would lead to fatal accumulation of DNA breaks. In our study, we found that loss of ICMT function results in the accumulation of DNA damages, leading to $\mathrm{G} 2 / \mathrm{M}$ arrest and apoptosis.

The accumulation of DNA damage associated with loss of ICMT could either be the result of elevated damage-inducing stresses or decreased repair capability. To distinguish the two possibilities, we

or ICMT-targeting shRNA were subcutaneously implanted in the flanks of SCID mice to form tumors. The tumor sizes of different groups at the time of treatment initiation are summarized in Fig S4A. Mice were treated with either vehicle control or $80 \mathrm{mg} / \mathrm{kg}$ niraparib and tumor growth monitored until termination of experiment. The tumor volumes of the indicated cell groups at the end of the study are graphed here. "**" $P<0.01$. The study is detailed in the Materials and Methods section. (C, D) Immunoblot analysis for ERK activation, p- $\gamma \mathrm{H} 2 \mathrm{AX}$, and cleaved caspase 7 on the lysates of the isolated tumors from (C). (E) Xenograft tumor growth of implanted MDA-MB231 cells treated with either vehicle control, $80 \mathrm{mg} / \mathrm{kg}$ niraparib alone, $100 \mathrm{mg} / \mathrm{kg}$ cysmethynil alone, or combination of niraparib and cysmethynil. Fifteen million MDA-MB231 parental cells were subcutaneously implanted in the flanks of SCID mice to form tumors. The tumor sizes of different groups at the time of treatment initiation are summarized in Fig S5A; tumor growth was monitored until termination of experiment (Fig S5B). The tumor volumes of the indicated cell groups at the end of the experiment are graphed here. “*” $P<0.05$; “**” $P<0.005 ;{ }^{* * * * ”} P<0.0005$. (E, F) TUNEL Assay to quantify apoptosis in the tumors isolated from (E). The left column: H\&E analysis images; the right column: TUNEL assay images; the four rows from top to bottom are vehicle, niraparib, cysmethynil, and combination treatment groups, respectively. Scale bar: $100 \mu \mathrm{m}$. (G) Immunoblot analysis on breast cancer cell lines MDA-MB157 and MDA-MB361 that are subjected to the treatment of either cysmethynil alone or combination of cysmethynil and niraparib. The cells were treated for $48 \mathrm{~h}$ before lysate preparation for SDS-PAGE and immunoblotting for the indicated proteins. For immunoblots, the numbers below each marker are the densitometry quantification of band intensity. For all immunoblots, the numbers below each marker are the densitometry quantification of band intensity relative to the control. 
A

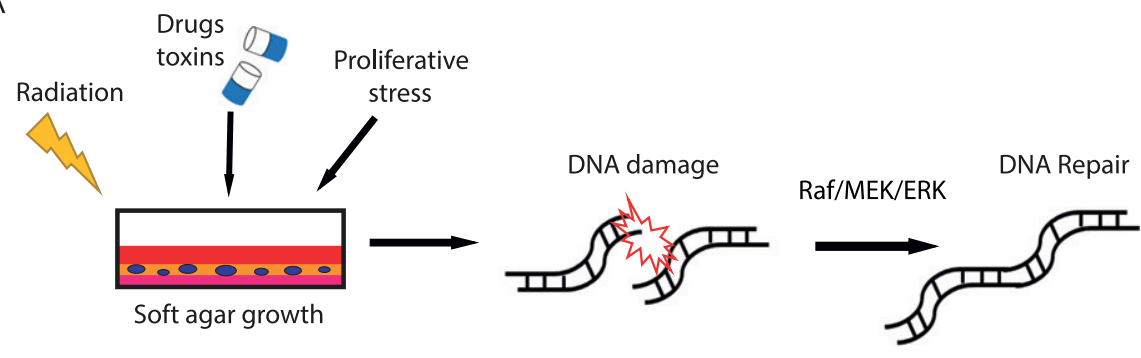

B

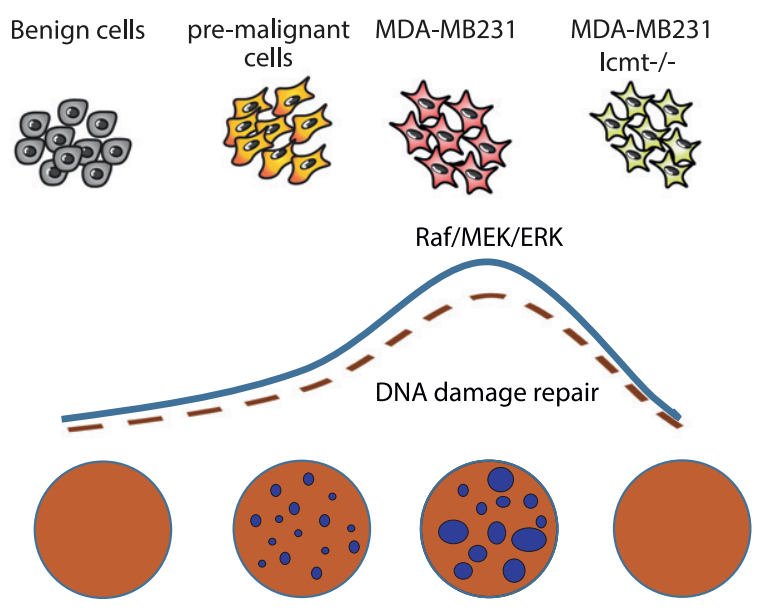

Figure 8. Schematic summary of key findings from the study.

(A) Exposure to drug/toxin, irradiation and suspension growth condition all cause DNA damage; the repair of the DNA damage requires active MAPK signaling.

(B) Malignant transformation in many cancers, such as in breast epithelial cells, increases the activation of MAPK signaling, which enhances the cells' ability to repair DNA damages and survive in suspension culture. Loss of ICMT function inhibits the MAPK activation, which impairs the DNA damage repair and increases apoptosis, leading to the abolishment of colony and tumor formation. (C) Loss of ICMT function in MDA-MB231 cells impairs DNA damage repair and renders them susceptible to PARP inhibitor treatment.
C

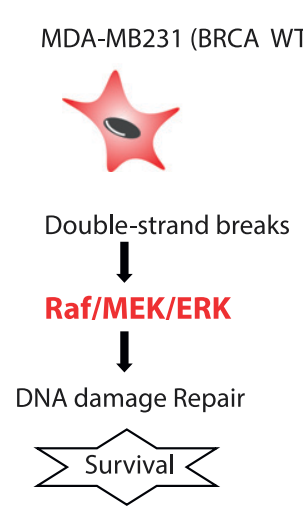

treated both $1 \mathrm{cmt}^{+/+}$and $\mathrm{Icmt}^{-/-}$cells with irradiation mimic drug zeocin to induce DNA damage and then observed the rate of damage repair during drug-free recovery period. Using comet assay and DNA damage marker analysis, the post zeocin recovery study led us to conclude that ICMT function is important for the repair of DNA damage. Interestingly, we found that in addition to the usual stressors such as irradiation and toxins, growing under suspension condition is an independent inducer for DNA damage. In fact, the accumulation of $\mathrm{p}-\mathrm{\gamma H}_{2} \mathrm{AX}$ in the $1 \mathrm{cmt}^{-/-}$cells was most pronounced only when the cells were cultured in soft agar condition.

In the investigation for the mechanism of ICMT regulation of DNA damage repair, we looked at major signaling pathways in cancer, particularly the ones involving key ICMT substrates; the reduction of MAPK signaling is the most consistent when ICMT is suppressed in MDA-MB231 isogenic cells (Fig 4A), which is cogent with the fact that it is directly under the regulation of RAS oncogenes-well-known ICMT substrates $(42,45,68)$. Up to now, the roles of MAPK in DNA damage and survival in cancer cells are not well-defined. Some studies have shown that activation of ERK, either from chemotherapy or from radiation, induced DNA damage $(52,53,54,57,94)$. In these settings, suppressing ERK activation reduced cell death induced by DNA damage $(96,97)$. Yet, other studies demonstrated that ERK is important for HR DNA repair, which is compromised by loss of ERK activation $(58,59)$. In the current study, we observed that 
maintaining MAPK activation is critical for the DNA damage repair in breast epithelial cancers, assessed by multiple breast cancer cell lines; the much suppressed MAPK signaling from the loss of ICMT leads to marked accumulation of DNA damage and apoptosis. Further strengthening the relevance of MAPK signaling in ICMTdependent DNA damage repair, expression of constitutively activate CRAF-22W in the I $\mathrm{cm}$ t null cells restored DNA damage repair capacity, reduced apoptosis and restored cells' ability to form colonies in soft agar (Fig 5). Consistently, MEK inhibitor treatment of MDA-MB231 cells induces the accumulation of DNA damage, G2/M arrest and apoptosis in a dose-dependent manner in soft agar (Fig 4). Finally, in the telomerase immortalized human mammary epithelial (HME-hTERT) cells, we observed that the transformation state induced by p53 knocking-down and mutant RAS expression (HME-shp53-Ras) increases MAPK signaling and reduces $\mathrm{pyH} 2 \mathrm{AX}$ and cleaved caspase 7 cleavage. In the established cancer cell line MDA-MB231, which has a highly activated MAPK pathway, loss of ICMT reduced the MAPK activation leading to DNA damage accumulation and apoptosis (Fig S7). Hence, we postulate that MAPK pathway promotes malignant transformation by maintaining DNA damage repair capability and safe guard cell survival (Fig 8B).

It is widely recognized that accumulation of a significant amount of damaged DNA is a trigger for the halting of cell cycle progression and induction of apoptosis (98). Thus, measures that increase DNA damage and/or decrease the cells' capacity for DNA repair have potential therapeutic benefit. In this regard, PARP1 inhibitors compromise the repair of DNA breaks leading to the accumulation of double-strand DNA breaks in proliferating cells $(17,18)$. Although it is increasingly recognized that PARP1 inhibitors suppress DNA repair in multiple ways, they generally work better through the mechanism of synthetic lethality with DNA repair deficiencies, endogenous or induced $(99,100)$. The efficacy of PARP inhibitors is much diminished in cancers that have intact, or even enhanced ability for DNA repair and tolerability for genomic instability (12, 101). Therefore, for many cancers the synthetic lethality needs to be created by combining PARP1 inhibition with an agent that compromises DNA damage repair or increases DNA damage (102) (Fig $8 \mathrm{C})$. The evidence presented in this study has identified a novel function of ICMT in DNA damage repair through its regulation of MAPK signaling. From this standpoint, it is a potential strategy to induce DNA damage and apoptosis by ICMT inhibition, either as a single agent or in combination with DNA damage-inducing agents such as PARP inhibitors or irradiation to achieve broader efficacy against resistant cancer cells (Fig 8C).

\section{Materials and Methods}

\section{Cell culture}

MDA-MB231, 436, 157, 361, and 453; HCC38, HME-1; and HEK293T cells, obtained from American Type Culture Collection, were cultured in high glucose DMEM or RPMI1640 (HCC38) containing 10\% fetal bovine serum and $1 \%$ penicillin/streptomycin. Human mammary epithelial (HME-1) cells that express human telomerase (HME-1hTERT), both human telomerase and SV40 small T antigen (HME-1-
ST), and HME-1-ST with additional shRNA targeting p53 and expressing mutant KRAS (HME-1-shp53-kRAS) were cultured as previously described (Lau et al, 2017) (44). For soft gar colony formation assay, low-gelling-temperature agarose, noble agar, DMEM-high glucose powder, PI and methylthiazolyldiphenyltetrazolium bromide (MTT) from Sigma-Aldrich were the reagents used. The bottom agar layer contains DMEM, 10\% FBS, and 0.5\% noble agar. The cells are mixed with $0.25 \%$ noble agar DMEM with $10 \%$ FBS. For the HME cells, the media on top was DMEM plus $10 \%$ FBS, $0.5 \mu \mathrm{g} / \mathrm{ml}$ hydrocortisone and $5 \mu \mathrm{g} / \mathrm{ml}$ insulin, whereas for MDA-MB231 cells it was DMEM and 10\% FBS. Cells were maintained in such condition for 2-3 wk and then developed by incubating in $0.2 \mathrm{mg} / \mathrm{ml}$ methylthiazolyldiphenyl-tetrazolium bromide (MTT) solution for $3-5 \mathrm{~h}$ at $37^{\circ} \mathrm{C}$. The colonies were visualized and imaged by Olympus SZX16 Research Stereo Microscope with a 2.5× objective. More than five randomly chosen views were analyzed for each colony formation conditions using OpenCFU software.

\section{Reagents and antibodies}

The MEK inhibitor PD184352, Bleomycin, Thymidine, Puromycin Hydrocortisone, and PI were purchased from Sigma-Aldrich; Hygromycin was from Invitrogen; Insulin was from I-DNA Biotech; and Triciribine (S1117) and niraparib (HY-10619) were purchased from Selleckchem and MCE (MedChemExpress), respectively; cysmethynil was synthesized by Duke University Small Molecule Synthesis Facility. All antibodies, including those for $\beta$-actin, pMEK (\#9121), MEK, pERK (\#4377), ERK, cleaved Cas7 (\#8438), p-yH2AX (\#9718), pCDC2 (\#4539), total-CDC2 (\#28439), cyclin B1 (\#4135), GAPDH (\#5174), phospo-DNAPKs (2056), cyclin D1 (\#2922), pAKT (\#9271S), and total AKT (\#9272S) were purchased from Cell Signaling Technology. TUNEL Assay Kit (ab206386) for tissue apoptosis study was from Abcam and used per manufacture's protocol.

\section{Cloning of shRNA and CDNA into lentiviral and retroviral vectors and selection of stable cell lines}

shRNAs targeting ICMT were cloned into lentiviral vector pLL3.7, whereas the cDNA encoding constitutively active c-RAF (RAF-22W) and p110-CAAX were cloned into pBabe-Puromycin vector. Lentivirus preparation and stable cell line selection are described in our previous publications $(44,47,103)$. PHR'CMV Citrine-geminin and PHR'CMV mCherry-cdt1 were purchased from Addgene; retrovirus preparation was as described previously (44).

\section{Immunoblot and quantitative-real time polymerase chain reaction analysis}

The cells were harvested in RIPA lysis buffer (Thermo Fisher Scientific) containing protease and phosphatase inhibitors (SigmaAldrich). Cell lysates were separated by standard SDS-PAGE, transferred to PVDF-FL membranes, blotted with primary antibody solution in PBST overnight at $4^{\circ} \mathrm{C}$, washed three times with PBST, and then incubated in respective secondary antibodies at 1:10,000 at room temperature for $1 \mathrm{~h}$. Membranes were washed multiple times with PBST before visualization using the Thermo Fisher Scientific SuperSignal West Femto Substrate (Thermo Fisher Scientific) and 
Bio-Rad ChemidoC. The images were analyzed and presented using the ImageLab software.

For PCR analysis, cDNA was generated from RNA samples using iScript CDNA Synthesis Kit (Bio-Rad). qRT-PCR was performed using the Thunderbird SYBR qPCR Mix (Toyobo) and the CFX96 Real Time System (Bio-Rad), followed by gene expression data analysis using the comparative CT method.

Primers used for the qPCR are listed below (from $5^{\prime}$ to $3^{\prime \prime}$ ):

BRCA1-F: CTGAAGACTGCTCAGGGCTATC, BRCA1-R: AGGGTAGCTGTTA GAAGGCTGG;

BRCA2-F: GGCTTCAAAAAGCACTCCAGATG，BRCA2-R: GGATTCTGTATCT CTTGACGTTCC;

BRIP1-F: TCTGGAGTTGGTGAAGACAGTCA, BRIP1-R: CCACGACAAACTGC TACCAGGA;

NBS1-F: TCTGTCAGGACGGCAGGAAAGA，NBS1-R: CACCTCCAAAGACAA CTGCGGA;

KU80/XRCC5-F: GCAGTGTCACCTCTGTTGGA, KU80/XRCC5-R: GCTCGGA TGCAGTCTATGCT;

XRCC2-F: TCTGTTTGCTGATGAAGATTCACC, XRCC2-R: CATCGTGCTGTTA GGTGATAAAGC;

MRE11-F: GCCTTCCCGAAATGTCACTA， MRE11-R: TTCAAAATCAACCCCT TTCG;

ERCC1-F: CGGCGGAAACTCATCCGATA， ERCC1-R: CCATCAGGGCCTCCT CAAAG;

RAD51-F: TCTCTGGCAGTGATGTCCTGGA, RAD51-R: TAAAGGGCGGTGGCA CTGTCTA;

RAD50-F: GCGGAGTTTTGGAATAGAGGAC, RAD50-R: GAGCAACCTTGGGA TCGTGT;

XRCC1-F: TCTCCCGGGTGACTGAATGTC， XRCC1-R: CCCCAACTCCTTGGG TTCTT;

XRCC4-F: TGGACTGGGACAGTTTCTGA, XRCC4-R: TCAGTTCACCAACATAT TTCCC.

\section{Thymidine cell synchronization assay}

Cells grown to $30-40 \%$ confluency were treated with $2 \mathrm{mM}$ thymidine in DMEM medium for $14 \mathrm{~h}$ in $37^{\circ} \mathrm{C}$ cell culture incubator. After PBS washing, the cells were then cultured in the standard DMEM medium for $9 \mathrm{~h}$. The second thymidine block was started by incubating the cells in DMEM with $2 \mathrm{mM}$ thymidine for $14 \mathrm{~h}$, followed by the culturing in the normal DMEM medium for the release step. Cells were harvested by trypsinization after $0,2,4$, and $8 \mathrm{~h}$ of release. Subsequently, the harvested cells were washed twice with PBS, fixed in $70 \%$ ethanol in $4^{\circ} \mathrm{C}$ overnight, treated with $200 \mu \mathrm{g} / \mathrm{ml}$ RNase A in PBS at $37^{\circ} \mathrm{C}$ for 30 min, stained with $50 \mu \mathrm{g} / \mathrm{ml} \mathrm{PI}$ in PBS overnight, and then analyzed by MACSQUANT Flow Cytometry for cell cycle distribution. The data analysis was carried out using Flowjo-10 software.

\section{Analysis of DNA damage by alkaline lysis comet assay}

Cells ready for the assessment, after appropriate treatment for each experiment, were embedded in $1 \%$ low-gelling-temperature agarose at $20,000 / \mathrm{ml}$ on the iBID chamber slides (\#80426; iBIDI $\mathrm{GmbH}$ ), which was submerged in the lysis buffer (1.2 M NaCl, $100 \mathrm{mM}$ sodium EDTA, $0.1 \%$ sodium lauryl sarcosinate, and $0.26 \mathrm{M} \mathrm{NaOH}$ ) overnight at $4^{\circ} \mathrm{C}$ in the dark. After the lysis step, the slides were washed three times with running solution which contained $0.03 \mathrm{M}$ $\mathrm{NaOH}$ and $2 \mathrm{mM} \mathrm{Na} \mathrm{F}_{2}$ EDTA in Milli $\mathrm{Q}$ water. The slides were then submerged in the electrophoresis chamber filled with running buffer and electrophoresed at $40 \mathrm{~mA}$ for $20 \mathrm{~min}$, followed by washing in Milli Q water for three times, before staining with 2.5 $\mu \mathrm{g} / \mathrm{ml} \mathrm{Pl}$ for $15 \mathrm{~min}$. The cells in the gel were imaged using Olympus IX71S1F3 Fluorescent Microscope. Data were analyzed by Casplab; at least 200 cells were analyzed for each condition.

\section{Macromolecule extraction from cells embedded in soft agar}

Protein and RNA extractions from cells embedded in soft agar were performed as recently detailed (104). Briefly, for protein analysis the cells were extracted with PBS and then snap frozen in liquid nitrogen and stored in $-80^{\circ} \mathrm{C}$ for further processing. The thawed pellet was mixed with RIPA buffer containing protease and phosphatase inhibitors at 1 to 0.5 volume ratio; $\beta$-mercaptoethanol was added to $2 \%$ final concentration and the samples are heated at $\geq 95^{\circ} \mathrm{C}$ for $10 \mathrm{~min}$, cooled on ice for $1 \mathrm{~h}$, and centrifuged at $15,000 \mathrm{~g}$ for $30 \mathrm{~min}$ at $4^{\circ} \mathrm{C}$. The supernatant was mixed vigorously with 1 volume of $100 \%$ methanol and 0.25 volume of chloroform, and the precipitated protein was pelleted. Pellets were air-dried and resuspended in the appropriate amount of RIPA buffer + protease and phosphatase inhibitors for subsequent analysis.

For RNA extraction, the layer of agar containing the cells was homogenized in a 0.4 volume ratio of pre-warmed $\left(65^{\circ} \mathrm{C}\right.$, in the dark) CTAC buffer, which contains $2 \%$ wt/vol cetyltrimethylammonium chloride (CTAC; Sigma-Aldrich), $2 \%$ wt/vol polyvinylpyrrolidone (PVP40; Sigma-Aldrich), 2 M sodium chloride, $100 \mathrm{mM}$ Tris- $\mathrm{HCl}$ at pH 8.0, 20 mM EDTA (Sigma-Aldrich); an equal volume of chloroform (SigmaAldrich) was then added and mixed vigorously. The mixture was centrifuged at 15,000 g for $5 \mathrm{~min}$ at room temperature, and the top layer removed and mixed with an equal volume of isopropanol to precipitate nucleic acid. After centrifugation at 15,000 $\mathrm{g}$ for $15 \mathrm{~min}$ at room temperature, the nucleic acid pellet was washed with $70 \%$ ethanol, pelleted at 15,000 $\mathrm{g}$ for $5 \mathrm{~min}$, and air-dried. The pellet was resuspended in $50 \mu \mathrm{l}$ RNase-free water and incubated with $1 \mu \mathrm{l}$ DNase I (Thermo Fisher Scientific) at $37^{\circ} \mathrm{C}$ for $30 \mathrm{~min}$. RNA was collected using the FavorPrep Tissue Total RNA Mini Kit (Favorgen, state, country) following the modified protocol as recently reported (104). To obtain DNA, RNase-free water was used to resuspend airdried nucleic acid pellet, which then was incubated with RNase A (QIAGEN) at $37^{\circ} \mathrm{C}$ for 30 min to degrade RNA. DNA was collected using the DNeasy Blood and Tissue Kit (QIAGEN) per manufacture's protocol.

\section{Xenograft mouse model in vivo study and tumor tissue analysis}

To generate xenograft tumors, 15 million MDA-MB231 breast cancer cells were subcutaneously implanted in the flanks of female SCID mice 8 wk of age, followed by tumor growth monitoring. Mice were orally dosed with either vehicle, $80 \mathrm{mg} / \mathrm{kg}$ niraparib daily, IP dosed $100 \mathrm{mg} / \mathrm{kg}$ cysmethynil every other day, or the combination of same doses of niraparib and cysmethynil for the treatment, as specified by each study, starting when the tumors reached the stable volume of $100-500 \mathrm{~mm}^{3}$. Tumor growth was followed until termination of 
experiment, which was when the fastest growing group of tumors, in this case the vehicle-treated control group, reached the mean size of $1,500 \mathrm{~mm}^{3}$. The study protocol was approved by the institutional Animal Care and Use Committee (IACUC). The tumors were isolated after mouse euthanization for imaging and sample preservation, which is by the standard fixation (HT501128; Sigma-Aldrich) and paraffin embedding method. Histology slide preparation and $\mathrm{H} \& \mathrm{E}$ staining were performed by Duke-NUS Histology Service. TUNEL assay to visualize apoptotic cells was per protocol of the manufacture of TUNEL Assay Kit (ab206386; Abcam).

\section{Statistical analysis}

All the statistical analysis in this study was performed using GraphPad Prism software; data are presented as mean \pm SD. To calculate the statistical significance, experimental groups were compared with the control group using Dunnett's test one-way ANOVA to generate $P$-values. Statistical significance was defined as $P<0.05$.

\section{Data Availability}

All data that support the findings of this study are openly available or on request from the corresponding author.

\section{Supplementary Information}

Supplementary Information is available at https://doi.org/10.26508/lsa. 202101144

\section{Acknowledgements}

The study is supported by Ministry of Education of Singapore (MOE2017-T2-1039) and National Medical Research Council Individual Grant (NMRC/CIRG/ 1486/2018).

\section{Author Contribution}

J Tang: conceptualization, data curation, formal analysis, validation, investigation, visualization, methodology, and writing-original draft, review, and editing.

PJ Casey: resources, formal analysis, validation, visualization, and writing-review and editing.

M Wang: conceptualization, resources, data curation, formal analysis, supervision, funding acquisition, validation, investigation, visualization, methodology, project administration, and writing-original draft, review, and editing.

\section{Conflict of Interest Statement}

The authors declare that they have no conflict of interest.

\section{References}

1. Lord CJ, Ashworth A (2012) The DNA damage response and cancer therapy. Nature 481: 287-294. doi:10.1038/nature10760

2. Helleday T, Petermann E, Lundin C, Hodgson B, Sharma RA (2008) DNA repari pathways as targets for cancer therapy. Nat Rev Cancer 8: 193-204. doi:10.1038/nrc2342

3. Sasaki MS, Ejima Y, Tachibana A, Yamada T, Ishizaki K, Shimizu T, Nomura T (2002) DNA damage response pathway in radioadaptive response. Mutat Res 504: 101-118. doi:10.1016/s0027-5107(02)00084-2

4. Rastogi RP, Richa, Kumar A, Tyagi MB, Sinha RP (2010) Molecular mechanisms of ultraviolet radiation-induced DNA damage and repair. J Nucleic Acids 2010: 592980. doi:10.4061/2010/592980

5. Woods D, Turchi JJ (2013) Chemotherapy induced DNA damage response: Convergence of drugs and pathways. Cancer Biol Ther 14: 379-389. doi:10.4161/cbt.23761

6. Barzilai A, Yamamoto K (2004) DNA damage responses to oxidative stress. DNA Repair (Amst) 3: 1109-1115. doi:10.1016/j.dnarep.2004.03.002

7. Hills SA, Diffley JFX (2014) DNA replication and oncogene-induced replicative stress. Curr Biol 24: R435-R444. doi:10.1016/j.cub.2014.04.012

8. Schär P (2001) Spontaneous DNA damage, genome instability, and cancer 0 when DNA replication escapes control. Cell 104: 329-332. doi:10.1016/s0092-8674(01)00220-3

9. Shaltiel IA, Krenning L, Bruinsma W, Medema RH (2015) The same, only different-DNA damage checkpoints and their reversal throughout the cell cycle. J Cell Sci 128: 607-620. doi:10.1242/jcs.163766

10. Shiotani B, Zou L (2009) Single-stranded DNA orchestrates an ATM-toATR switch at DNA breaks. Mol Cell 33: 547-558. doi:10.1016/ j.molcel.2009.01.024

11. Shen T, Huang $S$ (2012) The role of Cdc25A in the regulation of cell proliferation and apoptosis. Anticancer Agents Med Chem 12: 631-639. doi:10.2174/187152012800617678

12. Khanna A (2015) DNA damage in cancer therapeutics: A boon or a curse? Cancer Res 75: 2133-2138. doi:10.1158/0008-5472.CAN-14-3247

13. Notoyama M, Naka K (2004) DNA damage tumor suppressor genes and genomic instability. Curr Opin Genet Development 14:11-16. doi:10.1016/ j.gde.2003.12.003

14. Gorgoulis VG, Vassiliou L-VF, Karakaidos P, Zacharatos P, Kotsinas A, Liloglou T, Venere M, Ditullio RA Jr., Kastrinakis NG, Levy B, et al (2005) Activation of the DNA damage checkpoint and genomic instability in human precancerous lesions. Nature 434: 907-913. doi:10.1038/ nature03485

15. Ghosal G, Chen I (2013) DNA damage to tolerance: A double-edged sword guarding the genome. Transl Cancer Res 2: 107-129. doi:10.3978/ j.issn.2218-676X.2013.04.01

16. Bouchard VJ, Rouleau M, Poirier GG (2003) PARP-1, a determinant of cell survival in reponse to DNA damage. Exp Hematol 31: 446-454. doi:10.1016/s0301-472x(03)00083-3

17. Pascal JM (2018) The comings and goings of PARP-1 in response to DNA damage. DNA Repair (Amst) 71: 177-182. doi:10.1016/j.dnarep.2018.08.022

18. McGlynn P, Lloyd RG (2002) Recombinational repair and restart of damaged replication forks. Nat Rev Mol Cell Biol 3: 859-870. doi:10.1038/ nrm951

19. Buisson R, Dion-Côté AM, Coulombe Y, Launay H, Cai H, Stasiak AZ, Stasiak A, Xia B, Masson JY (2010) Cooperation of breast cancer proteins PALB2 and piccolo BRCA2 in stimulating homologous recombination. Nat Struct Mol Biol 17: 1247-1254. doi:10.1038/nsmb.1915

20. Bertwistle D, Ashworth A (1999) The pathology of familial breast cancer: How do the functions of BRCA1 and BRCA2 relate to breast tumour pathology? Breast Cancer Res 1: 41-47. doi:10.1186/bcr12 
21. Gupta A, Yang Q, Pandita RK, Hunt CR, Xiang T, Misri S, Zeng S, Pagan J, Jeffery J, Puc J, et al (2009) Cell cycle checkpoint defects contribute to genomic instability in PTEN deficient cells independent of DNA DSB repair. Cell Cycle 8: 2198-2210. doi:10.4161/cc.8.14.8947

22. Tangutoori S, Baldwin P, Sridhar S (2015) PARP inhibitors: A new era of targeted therapy. Maturitas 81: 5-9. doi:10.1016/j.maturitas.2015.01.015

23. Jaspers JE, Kersbergen A, Boon U, Sol W, van Deemter L, Zander SA, Drost R, Wientjens E, Ji J, Aly A, et al (2013) Loss of 53BP1 causes PARP inhibitor resistance in Brca1-mutated mouse mammary tumors. Cancer Discov 3: 68-81. doi:10.1158/2159-8290.CD-12-0049

24. Barber LJ, Sandhu S, Chen L, Campbell J, Kozarewa I, Fenwick K, Assiotis I, Rodrigues DN, Reis Filho JS, Moreno V, et al (2013) Secondary mutations in BRCA2 associated with clinical resistance to a PARP inhibitor. J Pathol 229: 422-429. doi:10.1002/ path.4140

25. Li H, Liu ZY, Wu N, Chen YC, Cheng Q, Wang J (2020) PARP inhibitor resistance: The underlying mechanisms and clinical implications. Mol Cancer 19: 107. doi:10.1186/s12943-020-01227-0

26. Sun C, Fang Y, Yin J, Chen J, Ju Z, Zhang D, Chen X, Vellano CP, Jeong KJ, Ng PK, et al (2017) Rational combination therapy with PARP and MEK inhibitors capitalizes on therapeutic liabilities in RAS mutant cancers. Sci Transl Med 9: eaal5148. doi:10.1126/scitranslmed.aal5148

27. Stordal B, Timms K, Farrelly A, Gallagher D, Busschots S, Renaud M, Thery J, Williams D, Potter J, Tran T, et al (2013) BRCA1/2 mutation analysis in 41 ovarian cell lines reveals only one functionally deleterious BRCA1 mutation. Mol Oncol 7: 567-579. doi:10.1016/ j.molonc.2012.12.007

28. Mariano G, Ricciardi MR, Trisciuoglio D, Zampieri M, Ciccarone F, Guastafierro T, Calabrese R, Valentini E, Tafuri A, Del Bufalo D, et al (2015) PARP inhibitor ABT-888 affects response of MDA-MB-231 cells to doxorubicin treatment, targeting Snail expression. Oncotarget 6: 15008-15021. doi:10.18632/oncotarget.3634

29. Frizzell KM, Kraus WL (2009) PARP inhibitors and the treatment of breast cancer: Beyond BRCA1/2? Breast Cancer Res 11: 111. doi:10.1186/bcr2451

30. Carey JPW, Karakas C, Bui T, Chen X, Vijayaraghavan S, Zhao Y, Wang J, Mikule K, Litton JK, Hunt KK, et al (2018) Synthetic lethality of PARP inhibitors in combination with MYC blockade is independent of BRCA status in triple-negative breast cancer. Cancer Res 78: 742-757. doi:10.1158/0008-5472.CAN-17-1494

31. Sonnenblick A, de Azambuja E, Azim HA Jr., Piccart M (2015) An update on PARP inhibitors: Moving to the adjuvant setting. Nat Rev Clin Oncol 12: 27-41. doi:10.1038/nrclinonc.2014.163

32. González-Billalabeitia E, Seitzer N, Song SJ, Song MS, Patnaik A, Liu XS, Epping MT, Papa A, Hobbs RM, Chen M, et al (2014) Vulnerabilities of PTEN-TP53-deficient prostate cancers to compound PARP-PI3K inhibition. Cancer Discov 4: 896-904. doi:10.1158/2159-8290.CD-13-0230

33. Zhang FL, Casey PJ (1996) Protein prenylation: Molecular mechanisms and functional consequences. Annu Rev Biochem 65: 241-269. doi:10.1146/annurev.bi.65.070196.001325

34. Wang M, Casey PJ (2016) Protein prenylation: Unique fats make their mark on biology. Nat Rev Mol Cell Biol 17: 110-122. doi:10.1038/nrm.2015.11

35. Clarke S (1992) Protein isoprenylation and methylation at carboxylterminal cysteine residues. Annu Rev Biochem 61: 355-386. doi:10.1146/ annurev.bi.61.070192.002035

36. Hampton SE, Dore TM, Schmidt WK (2018) Rce1: Mechanism and inhibition. Crit Rev Biochem Mol Biol 53: 157-174. doi:10.1080/ 10409238.2018.1431606

37. Hollander I, Frommer E, Mallon R (2000) Human ras-converting enzyme (hRCE1) endoproteolytic activity on K-ras-derived peptides. Anal Biochem 286: 129-137. doi:10.1006/abio.2000.4795

38. Otto JC, Kim E, Young SG, Casey PJ (1999) Cloning and characterization of a mammalian prenyl protein-specific protease. I Biol Chem 274: 8379-8382. doi:10.1074/jbc.274.13.8379
39. Clarke S, Vogel JP, Deschenes RJ, Stock J (1988) Posttranslational modification of the Ha-ras oncogene protein: Evidence for a third class of protein carboxyl methyltransferases. Proc Natl Acad Sci U S A 85: 4643-4647. doi:10.1073/pnas.85.13.4643

40. Dai Q, Choy E, Chiu V, Romano J, Slivka SR, Steitz SA, Michaelis S, Philips MR (1998) Mammalian prenylcysteine carboxyl methyltransferase is in the endoplasmic reticulum. J Biol Chem 273: 15030-15034. doi:10.1074/ jbc.273.24.15030

41. Philips MR, Pillinger MH, Staud R, Volker C, Rosenfeld MG, Weissmann G, Stock JB (1993) Carboxyl methylation of Ras-related proteins during signal transduction in neutrophils. Science 259: 977-980. doi:10.1126/ science. 8438158

42. Winter-Vann AM, Casey PJ (2005) Post-prenylation-processing enzymes as new targets in oncogenesis. Nat Rev Cancer 5: 405-412. doi:10.1038/ nrc1612

43. Wahlstrom AM, Cutts BA, Liu M, Lindskog A, Karlsson C, Sjogren AK, Andersson KM, Young SG, Bergo MO (2008) Inactivating Icmt ameliorates K-RAS-induced myeloproliferative disease. Blood 112: 1357-1365. doi:10.1182/blood-2007-06-094060

44. Lau HY, Tang J, Casey PJ, Wang M (2017) Isoprenylcysteine carboxylmethyltransferase is critical for malignant transformation and tumor maintenance by all RAS isoforms. Oncogene 36: 3934-3942. doi:10.1038/onc.2016.508

45. Bergo MO, Gavino BJ, Hong C, Beigneux AP, McMahon M, Casey PJ, Young SG (2004) Inactivation of Icmt inhibits transformation by oncogenic KRas and B-Raf. J Clin Invest 113: 539-550. doi:10.1172/JCl18829

46. Do MT, Chai TF, Casey PJ, Wang M (2017) Isoprenylcysteine carboxylmethyltransferase function is essential for RAB4A-mediated integrin beta3 recycling, cell migration and cancer metastasis. Oncogene 36: 5757-5767. doi:10.1038/onc.2017.183

47. Chai TF, Manu KA, Casey PJ, Wang M (2020) Isoprenylcysteine carboxylmethyltransferase is required for the impact of mutant KRAS on TAZ protein level and cancer cell self-renewal. Oncogene 39: 5373-5389. doi:10.1038/s41388-020-1364-7

48. Wang M, Tan W, Zhou J, Leow J, Go M, Lee HS, Casey PJ (2008) A small molecule inhibitor of isoprenylcysteine carboxymethyltransferase induces autophagic cell death in PC3 prostate cancer cells. J Biol Chem 283: 18678-18684. doi:10.1074/jbc.M801855200

49. Wang M, Hossain MS, Tan W, Coolman B, Zhou J, Liu S, Casey PJ (2010) Inhibition of isoprenylcysteine carboxylmethyltransferase induces autophagic-dependent apoptosis and impairs tumor growth. Oncogene 29: 4959-4970. doi:10.1038/onc.2010.247

50. Manu KA, Chai TF, Teh JT, Zhu WL, Casey PJ, Wang M (2017) Inhibition of isoprenylcysteine carboxylmethyltransferase induces cell-cycle arrest and apoptosis through p21 and p21-regulated BNIP3 induction in pancreatic cancer. Mol Cancer Ther 16: 914-923. doi:10.1158/15357163.MCT-16-0703

51. Degirmenci U, Wang M, Hu J (2020) Targeting aberrant RAS/RAF/MEK/ ERK signaling for cancer therapy. Cells 9: 198. doi:10.3390/cells9010198

52. Yan Y, Black CP, Cowan KH (2007) Irradiation-induced G2/M checkpoint response requires ERK1/2 activation. Oncogene 26: 4689-4698. doi:10.1038/sj.onc.1210268

53. Basu A, Tu H (2005) Activation of ERK during DNA damage-induced apoptosis involves protein kinase Cdelta. Biochem Biophys Res Commun 334: 1068-1073. doi:10.1016/j.bbrc.2005.06.199

54. Tang D, Wu D, Hirao A, Lahti JM, Liu L, Mazza B, Kidd VJ, Mak TW, Ingram AJ (2002) ERK activation mediates cell cycle arrest and apoptosis after DNA damage independently of p53. J Biol Chem 277: 12710-12717. doi:10.1074/jbc.M111598200

55. Hamed H, Hawkins W, Mitchell C, Gilfor D, Zhang G, Pei XY, Dai Y, Hagan MP, Roberts JD, Yacoub A, et al (2008) Transient exposure of carcinoma cells to RAS/MEK inhibitors and UCN-01 causes cell death in vitro and in vivo. Mol Cancer Ther 7: 616-629. doi:10.1158/1535-7163.MCT-07-2376 
56. Jo SK, Cho WY, Sung SA, Kim HK, Won NH (2005) MEK inhibitor, U0126, attenuates cisplatin-induced renal injury by decreasing inflammation and apoptosis. Kidney Int 67: 458-466. doi:10.1111/j.15231755.2005.67102.x

57. Wu D, Chen B, Parihar K, He L, Fan C, Zhang J, Liu L, Gillis A, Bruce A, Kapoor A, et al (2006) ERK activity facilitates activation of the S-phase DNA damage checkpoint by modulating ATR function. Oncogene 25: 1153-1164. doi:10.1038/sj.onc.1209148

58. Golding SE, Rosenberg E, Neill S, Dent P, Povirk LF, Valerie K (2007) Extracellular signal-related kinase positively regulates ataxia telangiectasia mutated, homologous recombination repair, and the DNA damage response. Cancer Res 67: 1046-1053. doi:10.1158/00085472.CAN-06-2371

59. Dai Y, Chen S, Pei XY, Almenara JA, Kramer LB, Venditti CA, Dent P, Grant S (2008) Interruption of the Ras/MEK/ERK signaling cascade enhances Chk1 inhibitor-induced DNA damage in vitro and in vivo in human multiple myeloma cells. Blood 112: 2439-2449. doi:10.1182/blood-200805-159392

60. Marampon F, Gravina GL, Di Rocco A, Bonfili P, Di Staso M, Fardella C, Polidoro L, Ciccarelli C, Festuccia C, Popov VM, et al (2011) MEK/ERK inhibitor U0126 increases the radiosensitivity of rhabdomyosarcoma cells in vitro and in vivo by downregulating growth and DNA repair signals. Mol Cancer Ther 10: 159-168. doi:10.1158/1535-7163.MCT-10-0631

61. Park M, Chae HD, Yun J, Jung M, Kim YS, Han MH, Shin DY (2000) Constitutive activation of cyclin B1-associated cdc2 kinase overrides p53-mediated G2-M arrest. Cancer Res 60: 542-545.

62. Pomerening JR, Sontag ED, Ferrell JE Jr. (2003) Building a cell cycle oscillator: Hysteresis and bistability in the activation of Cdc2. Nat Cell Biol 5: 346-351. doi:10.1038/ncb954

63. Sakaue-Sawano A, Kurokawa H, Morimura T, Hanyu A, Hama H, Osawa H, Kashiwagi S, Fukami K, Miyata T, Miyoshi H, et al (2008) Visualizing spatiotemporal dynamics of multicellular cell-cycle progression. Cell 132: 487-498. doi:10.1016/j.cell.2007.12.033

64. Yu T, MacPhail SH, Banáth JP, Klokov D, Olive PL (2006) Endogenous expression of phosphorylated histone H2AX in tumors in relation to DNA double-strand breaks and genomic instability. DNA Repair (Amst) 5: 935-946. doi:10.1016/j.dnarep.2006.05.040

65. Końca K, Lankoff A, Banasik A, Lisowska H, Kuszewski T, Góźdź S, Koza Z, Wojcik A (2003) A cross-platform public domain PC image-analysis program for the comet assay. Mutat Res 534: 15-20. doi:10.1016/s13835718(02)00251-6

66. Ashby J, Tinwell H, Lefevre PA, Browne MA (1995) The single cell gel electrophoresis assay for induced DNA damage (comet assay): Measurement of tail length and moment. Mutagenesis 10: 85-90. doi:10.1093/mutage/10.2.85

67. Olive PL, Banáth JP (2006) The comet assay: A method to measure DNA damage in individual cells. Nat Protoc 1: 23-29. doi:10.1038/nprot.2006.5

68. Winter-Vann AM, Baron RA, Wong W, dela Cruz J, York JD, Gooden DM, Bergo MO, Young SG, Toone EJ, Casey PJ (2005) A small-molecule inhibitor of isoprenylcysteine carboxyl methyltransferase with antitumor activity in cancer cells. Proc Natl Acad Sci U S A 102 4336-4341. doi:10.1073/pnas.0408107102

69. Bartkova J, Tommiska J, Oplustilova L, Aaltonen K, Tamminen A, Heikkinen T, Mistrik M, Aittomäki K, Blomqvist C, Heikkilä P, et al (2008) Aberrations of the MRE11-RAD50-NBS1 DNA damage sensor complex in human breast cancer: MRE11 as a candidate familial cancerpredisposing gene. Mol Oncol 2: 296-316. doi:10.1016/ j.molonc.2008.09.007

70. Matsumoto K, Nishimura M, Onoe T, Sakai H, Urakawa Y, Onda T, Yaegashi N (2019) PARP inhibitors for BRCA wild type ovarian cancer; gene alterations, homologous recombination deficiency and combination therapy. Jpn J Clin Oncol 49: 703-707. doi:10.1093/jjco/ hyz090
71. Suszynska M, Ratajska M, Kozlowski P (2020) BRIP1, RAD51C, and RAD51D mutations are associated with high susceptibility to ovarian cancer: mutation prevalence and precise risk estimates based on a pooled analysis of $\sim 30,000$ cases. J Ovarian Res 13: 50. doi:10.1186/s13048-02000654-3

72. Gachechiladze M, Škarda J, Soltermann A, Joerger M (2017) RAD51 as a potential surrogate marker for DNA repair capacity in solid malignancies. Int J Cancer 141: 1286-1294. doi:10.1002/ijc.30764

73. Hilbers FS, Wijnen JT, Hoogerbrugge N, Oosterwijk JC, Collee MJ, Peterlongo P, Radice P, Manoukian S, Feroce I, Capra F, et al (2012) Rare variants in XRCC2 as breast cancer susceptibility alleles. J Med Genet 49: 618-620. doi:10.1136/jmedgenet-2012-101191

74. Orelli B, McClendon TB, Tsodikov OV, Ellenberger T, Niedernhofer LJ, Schärer OD (2010) The XPA-binding domain of ERCC1 is required for nucleotide excision repair but not other DNA repair pathways. I Biol Chem 285: 3705-3712. doi:10.1074/jbc.M109.067538

75. Park DJ, Lesueur F, Nguyen-Dumont T, Pertesi M, Odefrey F, Hammet F, Neuhausen SL, John EM, Andrulis IL, Terry MB, et al (2012) Rare mutations in XRCC2 increase the risk of breast cancer. Am J Hum Genet 90: 734-739. doi:10.1016/j.ajhg.2012.02.027

76. Kuhfittig-Kulle S, Feldmann E, Odersky A, Kuliczkowska A, Goedecke W, Eggert A, Pfeiffer P (2007) The mutagenic potential of non-homologous end joining in the absence of the NHEJ core factors Ku70/80, DNA-PKcs and XRCC4-LigIV. Mutagenesis 22: 217-233. doi:10.1093/mutage/gem007

77. Heikkinen K, Karppinen SM, Soini Y, Mäkinen M, Winqvist R (2003) Mutation screening of Mre11 complex genes: Indication of RAD50 involvement in breast and ovarian cancer susceptibility. I Med Genet 40: e131. doi:10.1136/jmg.40.12.e131

78. Kuhfittig-Kulle S, Feldmann E, Odersky A, Kuliczkowska A, Goedecke W, Eggert A, Pfeiffer P (2007) The mutagenic potential of non-homologous end joining in the absence of the NHEJ core factors Ku70/80, DNA-PKcS and XRCC4-LigIV. Mutagenesis 22: 217-233. doi:10.1093/mutage/gem007

79. Suszynska M, Ratajska M, Kozlowski P (2020) BRIP1, RAD51C, and RAD51D mutations are associated with high susceptibility to ovarian cancer: Mutation prevalence and precise risk estimates based on a pooled analysis of $\sim 30,000$ cases. J Ovarian Res 13: 50. doi:10.1186/s13048-02000654-3

80. Haince JF, McDonald D, Rodrigue A, Déry U, Masson JY, Hendzel MJ, Poirier GG (2008) PARP1-dependent kinetics of recruitment of MRE11 and NBS1 proteins to multiple DNA damage sites. J Biol Chem 283: 1197-1208. doi:10.1074/jbc.M706734200

81. Liu Y, Burness ML, Martin-Trevino R, Guy J, Bai S, Harouaka R, Brooks MD, Shang L, Fox A, Luther TK, et al (2017) RAD51 mediates resistance of cancer stem cells to PARP inhibition in triple-negative breast cancer. Clin Cancer Res 23: 514-522. doi:10.1158/1078-0432.CCR-15-1348

82. Cruz C, Castroviejo-Bermejo M, Gutiérrez-Enríquez S, Llop-Guevara A, Ibrahim YH, Gris-Oliver A, Bonache S, Morancho B, Bruna A, Rueda OM, et al (2018) RAD51 foci as a functional biomarker of homologous recombination repair and PARP inhibitor resistance in germline BRCAmutated breast cancer. Ann Oncol 29: 1203-1210. doi:10.1093/annonc/ mdy099

83. Maresca L, Lodovichi S, Lorenzoni A, Cervelli T, Monaco R, Spugnesi L, Tancredi M, Falaschi E, Zavaglia K, Landucci E, et al (2018) Functional interaction between BRCA1 and DNA repair in yeast may uncover a role of RAD50, RAD51, MRE11A, and MSH6 somatic variants in cancer development. Front Genet 9: 397. doi:10.3389/fgene.2018.00397

84. Costantini S, Woodbine L, Andreoli L, Jeggo PA, Vindigni A (2007) Interaction of the Ku heterodimer with the DNA ligase IV/Xrcc4 complex and its regulation by DNA-PK. DNA Repair (Amst) 6: 712-722. doi:10.1016/ j.dnarep.2006.12.007

85. Pachkowski BF, Tano K, Afonin V, Elder RH, Takeda S, Watanabe M, Swenberg JA, Nakamura J (2009) Cells deficient in PARP-1 show an accelerated accumulation of DNA single strand breaks, but not AP sites, 
over the PARP-1-proficient cells exposed to MMS. Mutat Res 671: 93-99. doi:10.1016/j.mrfmmm.2009.09.006

86. D'Andrea AD (2018) Mechanisms of PARP inhibitor sensitivity and resistance. DNA Repair (Amst) 71: 172-176. doi:10.1016/ j.dnarep.2018.08.021

87. Jasin M (2002) Homologous repair of DNA damage and tumorigenesis: The BRCA connection. Oncogene 21: 8981-8993. doi:10.1038/sj.onc.1206176

88. Venkitaraman AR (2002) Cancer susceptibility and the functions of BRCA1 and BRCA2. Cell 108: 171-182. doi:10.1016/s0092-8674(02)00615-3

89. Keung MY, Wu Y, Badar F, Vadgama JV (2020) Response of breast cancer cells to PARP inhibitors is independent of BRCA status. J Clin Med 9: 940. doi:10.3390/jcm9040940

90. Lau HY, Ramanujulu PM, Guo D, Yang T, Wirawan M, Casey PJ, Go ML, Wang M (2014) An improved isoprenylcysteine carboxylmethyltransferase inhibitor induces cancer cell death and attenuates tumor growth in vivo. Cancer Biol Ther 15: 1280-1291. doi:10.4161/cbt.29692

91. Galaktionov K, Jessus C, Beach D (1995) Raf1 interaction with Cdc25 phosphatase ties mitogenic signal transduction to cell cycle activation. Genes Dev 9: 1046-1058. doi:10.1101/gad.9.9.1046

92. Karlsson-Rosenthal C, Millar JB (2006) Cdc25: Mechanisms of checkpoint inhibition and recovery. Trends Cell Biol 16: 285-292. doi:10.1016/j.tcb.2006.04.002

93. Zhou BB, Elledge SJ (2000) The DNA damage response: Putting checkpoints in perspective. Nature 408: 433-439. doi:10.1038/35044005

94. Wei F, Hao P, Zhang X, Hu H, Jiang D, Yin A, Wen L, Zheng L, He IZ, Mei W, et al (2018) Etoposide-induced DNA damage affects multiple cellular pathways in addition to DNA damage response. Oncotarget 9: 24122-24139. doi:10.18632/oncotarget.24517

95. Hills SA, Diffley JF (2014) DNA replication and oncogene-induced replicative stress. Curr Biol 24: R435-R444. doi:10.1016/j.cub.2014.04.012

96. Wong CH, Iskandar KB, Yadav SK, Hirpara JL, Loh T, Pervaiz S (2010) Simultaneous induction of non-canonical autophagy and apoptosis in cancer cells by ROS-dependent ERK and JNK activation. PLOS One 5: e9996. doi:10.1371/journal.pone.0009996

97. Srinivas US, Tan BWQ, Vellayappan BA, Jeyasekharan AD (2019) ROS and the DNA damage response in cancer. Redox Biol 25: 101084. doi:10.1016/ j.redox.2018.101084

98. Houtgraaf JH, Versmissen J, van der Giessen WJ (2006) A concise review of DNA damage checkpoints and repair in mammalian cells. Cardiovasc Revasc Med 7: 165-172. doi:10.1016/j.carrev.2006.02.002

99. Dedes KJ, Wilkerson PM, Wetterskog D, Weigelt B, Ashworth A, Reis-Filho JS (2011) Synthetic lethality of PARP inhibition in cancers lacking BRCA1 and BRCA2 mutations. Cell Cycle 10: 1192-1199. doi:10.4161/ cc.10.8.15273

100. Dedes KJ, Wetterskog D, Ashworth A, Kaye SB, Reis-Filho JS (2011) Emerging therapeutic targets in endometrial cancer. Nat Rev Clin Oncol 8: 261-271. doi:10.1038/nrclinonc.2010.216

101. Abulaiti A, Fikaris AJ, Tsygankova OM, Meinkoth JL (2006) Ras induces chromosome instability and abrogation of the DNA damage response. Cancer Res 66: 10505-10512. doi:10.1158/0008-5472.CAN-06-2351

102. Lord CJ, Ashworth A (2017) PARP inhibitors: Synthetic lethality in the clinic. Science 355: 1152-1158. doi:10.1126/science.aam7344

103. Kutner RH, Zhang XY, Reiser J (2009) Production, concentration and titration of pseudotyped HIV-1-based lentiviral vectors. Nat Protoc 4 : 495-505. doi:10.1038/nprot.2009.22

104. Lau HY, Tang J, Casey PJ, Wang M (2021) Evaluating the epithelialmesenchymal program in human breast epithelial cells cultured in soft agar using a novel macromolecule extraction protocol. Cancers (Basel) 13: 807 . doi:10.3390/cancers13040807

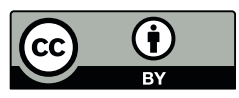

License: This article is available under a Creative Commons License (Attribution 4.0 International, as described at https://creativecommons.org/ licenses/by/4.0/). 